P\&T 22772

\title{
Emerging therapeutic targets in metastatic progression: a focus on breast cancer
}

\author{
Zhuo Li and Yibin Kang*
}

Department of Molecular Biology, Princeton University, Princeton, NJ, 08544, United States

* Corresponding author:

Department of Molecular Biology, LTL255

Washington Road,

Princeton University

Princeton, NJ 08544, United States

Tel: 609-258-8834; fax: 609-258-2340

E-mail address: ykang@princeton.edu (Y. Kang) 


\begin{abstract}
Metastasis is the underlying cause of death for the majority of breast cancer patients. Despite significant advances in recent years in basic research and clinical development, therapies that specifically target metastatic breast cancer remain inadequate, and represents the single greatest obstacle to reducing mortality of late-stage breast cancer. Recent efforts have leveraged genomic analysis of breast cancer and molecular dissection of tumor-stromal cross-talk to uncover a number of promising candidates for targeted treatment of metastatic breast cancer. Rational combinations of therapeutic agents targeting tumor-intrinsic properties and microenvironmental components provide a promising strategy to develop precision treatments with higher specificity and less toxicity. In this review, we discuss the emerging therapeutic targets in breast cancer metastasis, from tumor-intrinsic pathways to those that involve the host tissue components, including the immune system.
\end{abstract}

\title{
Keywords
}

Breast cancer, Metastasis, Targeted therapy, Tumor microenvironment, Immunotherapy 


\section{Contents}

1. Introduction

2. Status quo in the management of $\mathrm{mBC}$

3. Tumor-intrinsic targeting

4. Stroma-centric targeting

5. Conclusions and future directions

Acknowledgments

References

\section{Abbreviations}

ADC, antibody drug conjugate; AR, androgen receptor; CAF, cancer associated fibroblasts; GSI, gamma secretase inhibitor; HR, hormone receptor; mBC, metastatic breast cancer; MSC, mesenchymal stem/stromal cells; TAM, tumor-associated macrophages; TIL, tumor-infiltrating lymphocyte; TME, tumor microenvironment; TNBC, triple-negative breast cancer; T-reg, regulatory T cell. 


\section{Introduction}

The overall 5-year survival rate for breast cancer currently stands at $90 \%$ - a dramatic improvement over the $63 \%$ survival rate in the early 1960s. When stratified by stage, the 5 -year survival rates have increased to $99 \%$ for localized disease and 85\% for regional advanced disease, a trend that can be attributed to early diagnoses and better treatment regimens. However, for patients with advanced or metastasized breast cancer at the time of diagnosis (abbreviated as mBC in this review), the 5-year survival rate remains at only $26 \%$, reflecting a need for both new therapies and insights into the metastatic process. This disparity in survival between early and late stage breast cancer represents the principle obstacle in breast cancer management.

To date, the FDA has approved over 25 oncology drugs to treat breast cancer (Table 1). These drugs fall into three major categories: 1) Cytotoxic chemotherapies, including mitotic inhibitors, antimetabolites, and various DNA-damaging reagents; 2) Endocrine therapies, including selective estrogen receptor modulators (SERMs), aromatase inhibitors (AIs), and estrogen receptor downregulators (ERDs); and 3) Targeted therapies, which target certain dysregulated pathways in mBC or tumor microenvironment. The majority of these drugs belong to cytotoxic chemotherapies (44\%), followed by endocrine therapies (24\%) and HER2-targeting therapies (16\%). Only 4 drugs (16\%) target tumor- and microenvironment-specific molecules beyond the EGFR family, namely mTOR, CDK4/6, RANKL, and bisphosphonates.

The paucity of targeted therapies is further compounded by several critical issues in the management of mBC. The most crucial of these is the disparity in response rates to systemic chemotherapy, as only $50 \%$ of metastatic cancers respond in contrast to $90 \%$ of primary tumors . Lower response rate in mBC is also accompanied by a stronger likelihood of acquired therapeutic resistance during the course of treatment . Finally, the development of targeted agents for the highly metastatic triple-negative (TNBC) subtype has been 
largely hindered by a relative lack of understanding into its heterogeneous molecular nature . While targeting tumor-intrinsic factors remains the traditional approach to therapeutic intervention (i.e. targeting aberrant driver events in breast cancer cells), developing research on the tumor microenvironment suggests that a new paradigm of stroma-targeting may yield many novel opportunities. In particular, the use of immunotherapies to target $\mathrm{mBC}$ is a potentially promising field .

Here we review the current status of pharmacological management and focus on the landscape of emerging therapeutics for mBC. These include tumor-intrinsic targets such as the PI3K/ATK/mTOR pathway, PARP enzymes, activated growth factor receptors (e.g. EGFRs and FGFRs), cancer stem cell network (e.g. the Notch and Wnt pathways), androgen receptor, as well as therapies targeting communications between the tumor and host (e.g. immunotherapies). We discuss the mechanisms of action and biological implications of these targets with analysis of data from mechanistic and clinical studies. Finally, we address the need for the development of combinatorial therapies, in the context of targeting both the drivers of metastasis as well as the associated stromal components. 


\section{Status quo in the management of $\mathbf{m B C}$}

Clinical management of breast cancer has greatly improved in recent decades through the diagnostic classification of breast cancer into different subtypes, mainly on the basis of the hormone receptors (ER/PR) and the epidermal growth factor receptor HER2. Accordingly, breast cancer treatment is divided into three main classes: 1) hormone receptor-positive (ER+ and/or PR+), 2) ErbB2/HER2/neu-overexpressing (i.e. HER2+), and 3) the remaining TNBC marked by the absence of ER/PR and HER2, which are poorly characterized and the most difficult to manage.

Hormone receptor-positive $(\mathrm{HR}+) \mathrm{BC}$ patients are primarily treated with endocrine therapy (e.g. letrozole or tamoxifen), either alone or in combination with a cytotoxic chemotherapy drug. These patients generally have a favorable prognosis and are associated with better overall survival compared to the other subtypes.

However, HR+ patients also exhibit a higher risk of late recurrence following 5 years of adjuvant endocrine therapy, likely due to the low proliferation of HR+ tumor cells . Extended adjuvant endocrine therapy beyond 5 years has been shown to significantly reduce risk of recurrence and mortality in HR+ patients, and has been applied in clinical practice . The recent identification of activating mutations in the estrogen receptor (ESR1) demonstrates a central role of acquired endocrine resistance in $\mathrm{HR}+\mathrm{mBC}$, suggesting that second-line ER antagonists may be of substantial therapeutic benefit .

The more aggressive HER2+ BC is characterized by high expression of HER2/neu. These patients are primarily treated with trastuzumab (Herceptin), a landmark success in BC-targeted therapy. However, not all HER2+ tumors respond to anti-HER2 therapy. Although tumors resolve in many patients, others show no response or become resistant . Therefore, a multitude of HER2-targeting drugs exploiting different targeting mechanisms have been developed, such as lapatinib (HER2 and EGFR dual tyrosine kinase inhibitor) and 
pertuzumab (HER2 dimerization inhibitor) (see Table 1). Many other HER2-targeting strategies have been proposed and are currently under active investigations .

TNBC represents $15-20 \%$ of newly diagnosed breast cancer cases. These patients have a high risk of recurrence, especially in the brain and viscera. This high propensity to metastasize contributes to the worst rates of overall and disease free survival for TNBC patients compared to other subtypes . There are currently no targeted therapies available for these patients, leaving cytotoxic chemotherapies as the only standard of care. Treatment of TNBC remains one of the most pressing challenges in today's clinical practice. Addressing this need, gene expression profiling of over 3000 TNBCs has revealed a deeper stratification of six different TNBC subtype . Both this and other genomics-based studies continue to shed light on the molecular understanding of TNBC heterogeneity and may provide critical insights in developing TNBC-targeted therapies .

For breast cancer patients, metastasis to the bone is a common site of recurrence . This type of metastasis is characterized by a viscous cycle of bone resorption and accelerated tumor growth . Osteoclast inhibitors such as the bisphosphonates (e.g. pamidronate, zoledronic acid) and the RANKL-targeting denosumab have been repurposed for breast cancer patients with bone metastases, representing the only organ-tropic anti-metastatic treatment strategy currently available. Bisphosphonates are analogs of pyrophosphate that bind to the bone matrix and are internalized by osteoclast inhibitors. Once inside the cell, they inhibit osteoclast activity through a variety of means, such as acting as farnesyl-transferase inhibitors . Denosumab is a mAb that binds and inhibits receptor activator of nuclear factor kappa-B ligand (RANKL), the principle ligand responsible for the maturation of bone-resorbing osteoclasts . Both classes of drug effectively reduce the risk of skeletal- 
related events (SREs) in breast cancer patients with bone metastases, while denosumab has been shown superior to bisphosphonates in terms of both efficacy and tolerability .

Targeted drug delivery to cancer cells, exemplified by the antibody drug conjugate (ADC), has recently emerged as a novel and promising strategy in treating mBC. ADCs link potent chemotherapy drugs with monoclonal antibodies (mAbs) targeting cancer-specific antigens . Administration of ADCs leads to high intratumoral drug concentrations, while non-target tissues are largely spared from chemotherapeutic exposure . Ado-trastuzumab emtansine (Kadcyla, TDM-1), a HER2-targeting mAb trastuzumab conjugated with the microtubule-inhibitory agent DM1, was approved in 2013 for treating HER2+ mBC. Since, multiple ADCs have been developed to target various subtypes of breast cancer and are currently being tested in clinical trials (Table 2). 


\section{Tumor-intrinsic targeting}

Genomics studies have identified numerous genetic and pathway alterations in breast cancer cells, however, only a few have been validated as viable targets in clinical studies. Therapies against ER and HER2 highlight the landmark successes in targeted breast cancer treatment, suggesting that a tumor-intrinsic targeting approach is of significant value. In this section, we discuss several promising therapeutic candidates supported by strong clinical evidence (Figure 1).

\subsection{Inhibition of PI3K/AKT/mTOR pathway}

The PI3K/AKT/mTOR pathway mediates multiple cellular processes such as proliferation, migration, invasion, survival, metabolism, and angiogenesis . PIK3CA is one of the most frequently mutated genes in all subtypes of breast cancer . Its most prevalent activating mutation PIK3CA ${ }^{\mathrm{H} 1047 \mathrm{R}}$ has recently been shown to play key effects in tumor initiation and cell fate determination in the pre-neoplastic mammary gland . In addition, loss of PTEN and INPP4B are also frequently observed in breast cancer malignancies . Moreover, breast cancers that have constantly active Akt signaling will rely on Akt for survival and are associated with therapeutic resistance . Finally, crosstalk between the PI3K/AKT/mTOR and the Ras-MAPK pathways have been reported, creating a more complex network of signaling .

Disabling the PI3K/AKT/mTOR pathway provides a compelling and rational approach to improve the antitumor effects of existing chemotherapies. Activation of the PI3K/AKT/mTOR pathway is frequently implicated in resistance to endocrine, HER2-targeted and cytotoxic chemotherapies. Everolimus, a rapamycin analog that inhibits mTOR kinase activity, is the first and so far the only FDA-approved compound targeting this pathway. Small molecules designed to specifically target different components in the PI3K/AKT/mTOR pathway have been developed and are under active investigations in clinical trials (Table 
$3)$.

Alpelisib (also known as BYL719, PI3K $\alpha$ inhibitor), buparlisib (also known as BKM120, pan-PI3K inhibitor), taselisib (also known as GDC-0032, selective inhibitor of Class I PI3K $\alpha, \beta, \gamma$ isoforms), ipatasertib (also known as GDC-0068, ATP-competitive small molecule inhibitor of all three isoforms of Akt) have emerged as promising drug candidates. Alpelisib, buparlisib and taselisib demonstrate significant antitumor effects when combined with endocrine therapy . Combination of trastuzumab, LJM716 (HER3 mAb) and alpelisib has antitumor activity in pre-treated HER2+, PIK3CA-mutated mBC . The LOTUS (NCT02162719) trial is an ongoing phase II clinical trial to evaluate the efficacy of ipatasertib combined with paclitaxel in treatment of metastatic TNBC.

\subsection{Inhibition of PARP}

PARP inhibitors represent another emerging class of targeted therapeutics for mBC. PARP1, the first described enzyme of the PARP family, plays a key role in the repair of DNA single-strand breaks via base excision repair (BER); it has also been implicated in other pathways resolving or generating single-strand breaks, such as the nucleotide excision repair (NER) and mismatch repair (MMR) mechanisms . PARP1 inhibitors function by inhibiting the covalent attachment of ADP-ribose to PARP1 substrates, such that DNA repair enzymes cannot be recruited to the site of DNA damage . Studies indicate that PARP1 inhibitors have the most potent antitumor effects in cancers with BRCA-mutations, as double strand break repair via homologous recombination (HR) is not available in BRCA-defective cells . This creates a situation of synthetic lethality in which only the BRCA-mutated tumor cells are affected .

Olaparib is the only PARP inhibitor approved by the FDA, as a single-agent treatment for advanced ovarian 
cancer driven by defective BRCA genes. Olaparib has been tested in breast cancer as either a single agent or in combination with other cytotoxic drugs. The current clinical trials involving Olaparib primarily enrolled patients with BRCA-mutated mBC . Second-generation PARP inhibitors have also been developed and are being evaluated in multiple clinical trials (Table 4). Among the agents, veliparib (ABT888) and talazoparib (BMN 673) are the two most promising candidates that have entered phase III clinical trials.

Veliparib is a PARP inhibitor targeting both PARP1 and PARP2. Potential synergistic interactions between veliparib and cisplatin or the EGFR inhibitor lapatinib were reported to suppress TNBC cell lines . A phase III trial (NCT02163694) has been initiated in 2014 to assess efficacy and toxicity of veliparib in BRCA-

associated mBC. Talazoparib is a dual-mechanism PARP inhibitor that potently inhibits the PARP enzyme and effectively traps PARP on DNA. It selectively targets tumor cells with BRCA1, BRCA2, or PTEN gene defects with a high potency in cell lines and xenograft models . EMBRACA (NCT01945775) is an ongoing phase III trial evaluating the safety and efficacy of Talazoparib in mBC patients with BRCA mutations.

The use of synthetic lethality has been mostly studied in the context of BRCA1/2-deficient breast and ovarian cancers . Nevertheless, studies suggest that PARP1 inhibitors may also have positive effects in patients that are non-BRCA mutation carriers , possibly due to the less-defined roles of PARP in double strand-break repair, transcriptional regulation, and hormone-dependent cancers .

\subsection{Inhibition of activated growth factor receptors}

Increased expression of growth factor receptors and activation of their tyrosine kinase activities are frequently observed in breast cancers . Besides HER2, other members of the EGFR family (e.g. EGFR/HER1/ErbB1, HER3/ErbB3), vascular endothelial growth factor (VEGF) and its receptors (VEGFRs), fibroblast growth 
factor (FGF) and it receptors (FGFRs), platelet-derived growth factor (PDGF) and its receptors (PDGFRs), insulin-like growth factor-1 (IGF-1) and its receptor (IGF-1R), mast/stem cell growth factor receptor (SCFR, also known as c-Kit) , and MET and hepatocyte growth factor receptor (HGFR, also known as c-MET) have been found dysregulated (by amplification, translocations, or mutations) in breast tumors and are associated with poor patient outcomes.

Therapeutic agents targeting these growth factor-responsive tumors include blockade of individual receptors with mAbs and inhibition of tyrosine kinase activities with small molecule inhibitors. The clinical testing of the long-heralded VEGFR inhibitors failed in Phase II and III clinical trials (see section 4.1.2). Of the myriad growth factors, FGFR is an emerging target of promise. The FGF-FGFR signaling axis plays essential functions in regulating cell proliferation, survival, migration and differentiation in both normal and cancer development . Activation of FGFR signaling may lead to increased tumor angiogenesis and play a role in tumor resistance to antiangiogenic agents and other chemotherapies . In breast cancer, upregulation of the FGFR pathway activity could occur through multiple mechanisms. Amplification of FGFR1 (10\% of all BC), FGFR2 (4\% of TNBC) and FGFR4 genes (10\% of all BC), and germline single nucleotide polymorphisms (SNPs) of FGFR2 and FGFR4 have been reported and are associated with poor prognosis . Therapeutic agents targeting aberrant FGFR activation are now being evaluated in multiple phase II/III clinical trials (Table 5).

\subsection{Targeting cancer stem cell signaling}

TNBC represents a highly diverse group of cancers , and certain subtypes within this classification show a strong enrichment of cancer stem cell-like features . The cancer stem cell theory hypothesizes that a small fraction of the cells in a tumor have characteristics of somatic stem cells with highly tumorigenic and chemoresistant potential, and could be responsible for the majority of metastatic relapse . As such, the treatment of 
specific stem cell features may offer a curative approach to cancer therapy. The Notch and Wnt pathways are the two most extensively studied pathways that have been implicated in both normal and cancer stem cells of the mammary gland, and may be potential targets in TNBC .

\subsubsection{Targeting the Notch pathway}

Upregulated Notch signaling has been reported in TNBC, and is usually associated with the down-regulation of Numb or activating fusion mutations found in NOTCH1 or NOTCH2 (5-10\% of TNBC cases). Early attempts to target the Notch pathway focused on gamma secretase inhibitors (GSIs) (Table 6). Gamma secretase is a multi-protein integral membrane complex that catalyzes the proteolytic processing of Notch receptors and liberates the Notch intracellular domain (NCID); NCID subsequently translocates to the nucleus and regulates transcription of Notch downstream target genes . Clinical trials involving GSIs demonstrate the feasibility of targeting aberrant Notch signaling in treating mBC (Table 6). However, a low specificity for tumor cells induced high toxicity in GSI-treated patients .

Other Notch-targeting strategies to interfere with Notch signaling show promise in improving therapeutic specificity (Table 6). Antibodies against specific Notch ligands or receptors have been heavily studied in many cancer systems, and will provide an attractive alternative in treating mBC . For example, tumor-derived Jagged1, one of the five Notch ligands, has been shown to promote osteolytic bone metastasis in breast cancer by engaging Notch signaling in the bone cells . It is anticipated that more specific Notch-targeting approaches will rapidly expand as we gain increasing understanding of the Notch signaling network in breast cancer.

\subsubsection{Targeting the Wnt pathway}

Similar to Notch pathway, activated Wnt signaling has also been implicated in breast cancer tumorigenesis 
and recurrence . Canonical $\beta$ catenin-mediated WNT signaling supports self-renewal of both normal and malignant mammary stem cells . Activated canonical Wnt signaling has been observed in both the primary tumor and lung metastasis of TNBC/basal-like subtype, and is associated with poor clinical outcomes .

Somatic mutations in the Wnt pathway are uncommon in breast cancer; however, dysregulation of proteins in the signaling cascade have been reported. In breast cancer patients, WNT1 protein expression was increased in the tumor tissue compared with non-cancerous adjacent tissue . In this study, Wnt-1 was shown to be markedly elevated in low-grade tumors, but expression levels were reduced as the tumors progressed, suggesting a functional role of Wnt1 at early stages of tumorigenesis. Inhibition of Wnt1 expression reduces the enrichment of cancer stem cells in a mouse model of breast cancer . Receptor-tyrosine-kinase-like orphan receptor 1 (ROR1), a receptor in the non-canonical Wnt pathway, is found to be highly expressed in primary tumors of TNBC patients . ROR1 expression increases in TNBC samples relative to their corresponding normal controls, and correlates with decreased patient survival . ROR1-positive TNBC has been associated with EMT and stem cell-like phenotypes, suggesting that ROR1 might be a potential target for TNBC therapy . Together these studies suggest a potential for Wnt-targeted treatment in breast cancers, but the design of clinical trials should be carefully considered for specific subtypes and/or tumor grades.

\subsection{Androgen receptor (AR)}

The androgen receptor (AR) is a nuclear receptor activated by the binding of androgenic hormones in the cytoplasm and then translocating into the nucleus . Activated AR regulates gene transcription by binding to specific promoter sequences of target genes . Androgen contributes to the growth of certain types of cancers, most notably prostate cancer . Enzalutamide, an androgen receptor antagonist and potent inhibitor of AR signaling, has been approved for the treatment of metastatic castration-resistant prostate cancer. Although 
androgens are often considered to be male sex hormones, they also play important physiologic roles in females .

The prognostic power and clinical relevance of AR expression in breast cancer remains a topic of investigation, and is likely to be subtype-dependent. Some breast cancers express AR, and higher expression is more commonly seen in women with ER+ (67-95\%) breast cancer than in women with the HER2+ (63\%) or TNBC (10-43\%) subtypes . A systematic review and meta-analysis of AR expression and outcomes in early breast cancer concluded that the expression of AR in women with breast cancer is associated with better overall survival (OS) and disease-free survival (DFS) irrespective of ER status . Other studies indicated that AR expression is most significantly associated with a favorable prognosis in ER+ BC patients . While many retrospective histology-based analysis suggest that the presence of AR in breast cancer correlates with better survival outcome, other preclinical and clinical studies implicate that AR antagonists may improve the survival of AR+ TNBC patients . A subclass of TNBC was identified as the luminal androgen receptor (LAR) subtype, as characterized by expression of AR and AR gene targets; LAR cell lines were shown to be uniquely sensitive to AR antagonist bicalutamide .

Investigational trials using AR antagonists, either as monotherapy or combined with other drugs, in patients with $\mathrm{AR}+$ breast cancer are currently ongoing (Table 7). Most of these clinical trials focus on AR+ metastatic TNBC, and a few others target AR+/HR-/HER2+ or AR+/HR+/HER2- mBC subtypes. The discrepancy between the prognostic value of AR and the anti-AR treatment efficacy in clinical trials requires further translational investigations. Such studies will enable a better understanding of the biological functions of androgen and AR, and the mechanisms of action of anti-AR treatment in breast cancer patients. 


\section{Stroma-centric targeting}

Our knowledge of the stroma's contribution to cancer has rapidly grown in the past decade. Stromal cells in the tumor microenvironment (TME) play pivotal roles in facilitating multiple steps during cancer progression and metastasis . Therapeutics targeting tumor-stromal interactions and enhancing host immune response represents an attractive alternative to treat human breast cancer (Figure 2).

\subsection{Contributions of stromal cells in creating a favorable tumor microenvironment}

Myriad evidence has highlighted the importance of the crosstalk between tumor cells and their surrounding microenvironment . Cancer progression and metastasis are enabled, sustained, and co-evolved through interactions with the stromal cells. While these stromal cells are far from being fully characterized, they include infiltrating immune cells, endothelial cells, cancer-associated fibroblasts (CAFs), and mesenchymal stem/stromal cells (MSCs). . Cytokines and extracellular matrix (ECM) proteins provided by both the stromal and tumor cells facilitate breast cancer progression through a complex network of tumor-stromal communication . Heterogeneous cell types within the TME can also actively influence therapeutic responses and shape resistance .

\subsubsection{Infiltrating immune cells}

Myeloid lineage-derived macrophages can be recruited and educated by tumor cells and the TME to become tumor-associated macrophages (TAMs) or metastasis-associated macrophages (MAMs) . These TAMs and MAMs are immunosuppressive and contribute to tumor progression via numerous macrophage-derived signaling factors, such as cytokines, growth factors, matrix metalloproteinases (MMPs), and hypoxia response proteins . The tumor microenvironment of metastasis (TMEM), characterized by direct interaction between perivascular TAMs, endothelial cells and tumor cells, has been found in human breast cancer specimens . A 
high TMEM score is associated with increased risk of distant metastasis . Expression of Mena (INV), an invasive isoform of Mena, correlates with a high TMEM score and enhances transendothelial migration of breast cancer cells . This process has been shown to be mediated through paracrine and autocrine activation of colony-stimulating factor-1 receptor (CSF-1R) .

Preclinical and clinical observations suggest that macrophage-targeting therapies could be a feasible approach to treat breast cancer metastasis. CSF-1/CSF-1R is one of the most important signaling axes during the differentiation of myeloid progenitors to monocytes, macrophages, dendritic cells and bone-resorbing osteoclasts . Blocking macrophage recruitment using CSF-1R inhibitors, in combination with chemotherapy, decreases breast cancer progression and metastasis, and improves survival through CD8 ${ }^{+}$T-cell-dependent mechanisms in tumor-bearing mice . $\mathrm{T}_{\mathrm{H}}$ 2/M2-type macrophage-derived IL-10 was shown to mediate this $\mathrm{CD}^{+}$T-cell-dependent responses . Antibodies against CSF-1R reduced TAM numbers and translated into clinical responses in patients with diffuse-type giant cell tumor (Dt-GCT), a type of cancer that overexpresses CSF-1 . Small molecule inhibitors and mAbs against CSF-1R are currently evaluated in patients with advanced solid tumors (Table 8).

Myeloid-derived suppressor cells (MDSCs) are a heterogeneous population of immune cells from the myeloid lineage. MDSCs possess strong immunosuppressive activities, primarily through suppressing CD8+ T-cell cytotoxicity . MDSCs contribute to the establishment of an immunosuppressive pre-metastatic niche via tumor-derived factors such as GM-CSF, $\underline{\text { IL-6 }}$ and lysyl oxidase (LOX). Inhibition of LOX activity in tumor cells block myeloid cell recruitment to pre-metastatic niche and reduce breast cancer lung and bone metastasis, suggesting a possible strategy for therapeutic intervention. 
Regulatory T (T-reg) cell is another class of immunosuppressive cell that primarily functions to inhibit induction and proliferation of effector T cells. A significant increase of T-reg cells was observed in the peripheral blood and TME of invasive breast and pancreas cancer patient . Tumor-infiltrating T-reg cells, recruited by tumor-derived CCL5, could stimulate mammary cancer metastasis through RANKL-RANK signaling . In a breast cancer xenograft model, attenuation of a glycan-binding protein galectin-1 (Gal1) reduced the frequency of T-reg cells within the tumor and reduced lymph node, spleen, and lung metastases, suggesting the possibility of targeting Gal1 in breast cancer metastasis . Understanding the specific roles of Treg cells in cancer is the key for development of therapeutics against this class of immune cells

\subsubsection{Angiogenic vasculature}

Vascular endothelial cells and their supporting pericytes together form the angiogenic vasculature. The induction of angiogenesis (also known as angiogenic switch) promotes cancer cell proliferation. The angiogenic vasculature promotes tumor progression not only by supplying nutrients and oxygen, but also through an "angiocrine” mechanism by producing stem and progenitor cell-active factors, ECM components etc. to generate a tumor-favorable microenvironment .

VEGF is one of the most well-known angiogenic factors and has an established role in breast cancer . VEGFRs are tyrosine kinase receptors primarily expressed on endothelial cells, and are responsible for binding with VEGF to initiate signal cascades that stimulate angiogenesis and lymphangiogenesis . VEGFRs are up-regulated in multiple cancer types which have a high need for nutrients and oxygen, including breast cancer . Since early in this century, clinical trials involving mAbs or small molecule inhibitors that interrupt VEGF-VEGFR signaling have been conducted extensively in various cancer types. Despite the promising results from other cancer types (e.g. lung cancer, colorectal cancer, renal cell carcinoma (RCC), glioblastoma), 
most trials have failed to demonstrate a statistically significant survival advantage in mBC patients . This could be explained by several reasons, for example: drug resistance through activation of alternative angiogenic pathways, and lack of biomarkers to stratify patients that could benefit most from anti-VEGF therapy . Nevertheless, several recent studies shed light on potentially new directions for anti-VEGF therapies. For example, it was demonstrated that blocking lipid synthesis could overcome tumor regrowth and metastasis after antiangiogenic therapy withdrawal . Moreover, PD-L1 was shown to crosstalk with VEGFR2 during angiogenesis, and a combination of anti-VEGF and immunotherapeutic strategies may improve treatment efficacy in $\mathrm{mBC}$.

In addition to the VEGF-VEGFR axis, PDGF-PDGFR signaling has also been implicated in breast cancer tumor-stromal interaction. PDGFRs are expressed on breast cancer stromal cells and tumor-derived PDGFs stimulate the stromal cells to further promote tumorigenesis . PDGFRs are also expressed in invasive breast carcinomas, which correlate with tumor aggressiveness, higher chance of metastasis and shortened survival . Inhibition of PDGFR signaling has proven effective in patients with certain rare tumors, yet it remains to be examined whether this treatment will be beneficial for mBC patients.

\subsubsection{Cancer-associated fibroblasts (CAFs)}

CAFs are a heterogeneous population of fibroblasts residing within the TME and can facilitate malignant transformation and growth of cancer cells . CAFs secrete pro-proliferation signals (e.g. TGF- $\alpha$ ), proangiogenic signals (e.g. VEGF, FGF and PDGF) and pro-EMT signals (e.g. TGF- $\beta$ ) to facilitate tumor growth, angiogenesis and metastasis . CAFs can also modulate immune polarization in the TME and inhibit the antitumor activities of cytotoxic T cells and natural killer (NK) cells . CAFs in the primary breast TME were shown to select for bone specific metastatic traits in tumor cells via CAF-secreted CXCL12 and IGF1 . A 
small population of breast cancer stem cells induces periostin (POSTN) expression in resident fibroblasts at the secondary target organ in order to initiate metastasis colonization . Although CAFs are primarily studied as pro-tumorigenic stromal cells, recent studies suggested that tumor-resident fibroblasts could also have tumorinhibitory effects, suggesting a degree of plasticity in this stromal cell type .

\subsubsection{Mesenchymal stem/stromal cells (MSCs)}

MSCs are multipotent stromal cells that can differentiate into a variety of cell types such as osteoblasts, chondrocytes, adipocytes, myocytes, and cardiomyocytes . They are traditionally found in the bone marrow, but can also be isolated from cord and peripheral blood. Bone-marrow-derived MSCs have been shown to enhance breast cancer cell motility, invasion and metastasis, dependent on CCL5-CCR5 signaling between cancer cells and MSCs . Other studies also confirm that MSCs are able to supply contextual signals (e.g. CCL5, IL6, CXCL7, CXCL10, TGFß1) to the tumor-associated stroma, creating an immunosuppressive microenvironment and promoting metastatic progression . These signaling events have been observed between MSCs and breast cancer cells as well as between MSCs and other stromal cell types. Recent studies also highlighted the roles of MSC-associated microRNAs in regulating breast cancer progression . The therapeutic potential of targeting MSCs in mBC warrants further investigations as MSCs could be either tumor-promoting or tumor-suppressing depending on different environmental inflammatory conditions .

\subsection{Immunotherapies}

Historically, breast cancer has been considered poorly immunogenic, thus less responsive to immunotherapies. A few mechanisms may contribute to this. First, the percentages of both type1 (IL-2, IFNY or TNF $\alpha$ ) and type 2 (IL-4) cytokines produced by T lymphocytes were found significantly lower in the peripheral blood of patients with breast cancer compared to healthy controls, suggesting a general immune dysfunction in these 
patients . Second, myeloid suppressor cells, Th2 CD4+T cells and T-reg cells function together to create an immune-suppressive TME and suppress CD8+ cytotoxicity via cytokine signaling (e.g. IL-4, IL-13, IL-10, IL6 and TGF $\beta$ ) . Third, many cancer cells, including breast cancer, downregulate MHC molecules and/or costimulatory molecules and upregulate immunosuppressive factors such as PD-L1, resulting in immune escape .

Despite the less immunogenic nature, a small population of breast cancer do induce stronger cytotoxic T- and NK-cell responses, and tend to have a more favorable prognosis with a better response to chemotherapy . Recent studies suggest that significant immune cell infiltration via tumor-infiltrating lymphocytes (TIL) in early breast cancer predicts higher responses to chemotherapy, reduced risk of distant metastasis, and better overall survival, particularly in the TN and HER2+ subtypes . These observations suggest that immunotherapies could have potential to elicit strong immune response in at least a subset of mBC.

\subsubsection{Therapeutic vaccine}

Therapeutic vaccines are designed to elicit an immune response against tumor-associated antigens (TAAs) and enhance the host immune system to attack TTA-bearing cancer cells. Vaccination usually takes a relatively a long time (i.e. weeks to months) to produce enough antigen-specific cytotoxic T cell for an effective immune response , thus may not be the most appropriate treatment for patients in an advanced-disease setting. Most breast cancer vaccine clinical trials are studied in an adjuvant setting in early stage patients with minimal residual tumor cells. Vaccination in combination with other targeted therapies or immunotherapies in patients with high risk of recurrence provide an opportunity to boost and maintain the host immune response in order to eradicate the fewer number of isolated tumor cells before they have a chance to establish larger metastases (Table 8). 


\subsubsection{Immune checkpoint blockade}

After decades of incremental progresses, researchers have started to appreciate the therapeutic power of modulating activities of immune checkpoints, such as cytotoxic T lymphocyte-associated antigen 4 (CTLA-4) and programmed cell death protein 1 (PD-1) . Both CTLA-4 and PD1 belong to the CD28 family receptors and they transmit inhibitory signals to prevent T-cell activation. Blocking the functions of these checkpoint proteins liberates tumor-specific T cells to exert their effector function against tumor cells and subsequently induces a strong immune response . Immune checkpoint blockade have demonstrated promising activities in a variety of malignancies, including melanoma, RCC, head and neck, lung, bladder and prostate cancers . To date, the FDA has approved three such drugs for the treatment of metastatic melanoma and squamous nonsmall cell lung cancer: ipilimumab (Yervoy), pembrolizumab (Keytruda), and nivolumab (Opdivo). The first targets the CTLA-4 pathway and the latter two target PD-1.

PD-1 ligand (PD-L1) expression was observed in 30\% of breast cancer patients, and positively associated with HR-negative and triple-negative (TN) status and high levels of TILs . Clinical studies indicate that immune checkpoint blockade, in combination with cytotoxic drugs, have the potential to improve clinical outcomes for patients with mBC, especially metastatic TN and HER2+ breast cancer with lymphocytic tumor infiltrates at diagnosis . mAb targeting PD-1 (Pembrolizumab/MK-3475) or PD-L1 (MPDL3280A) demonstrated promising therapeutic activities in heavily pretreated metastatic TNBC . Multiple clinical trials, including a phase III trial of MPDL3280A, have been recently initiated in patients with mBC (Table 8).

Several other immunomodulatory agents which have the potential to enhance anti-tumor immune response were also reported. For example, indoleamine-pyrrole 2, 3-dioxygenase (IDO) is an immune checkpoint 
molecule expressed on various stromal cells such as macrophages . IDO is also expressed by a number of tumor types that possess an immune-escape strategy, and is correlated with poor prognosis . Another example is OX40, a potent TNF receptor family co-stimulatory receptor that can potentiate $\mathrm{T}$ cell receptor signaling. Ligation of OX40 with an agonistic anti-OX40 mAb has been shown to enhance anti-tumor immunity . Phase II trials of IDO inhibitor and anti-OX40 mAb are currently being tested in mBC patients (Table 8). Additional therapeutic targets involved in anti-cancer immune response include T-cell immunoglobulin and mucin domain-containing protein 3 (TIM-3) , lymphocyte-activation gene 3 (LAG-3) , and the costimulatory receptor of the TNF receptor family CD137 .

A small subset of HER2+ and TNBC patients that have relatively high levels of TILs might benefit most from current immune checkpoint inhibitors. Those patients that have no or relatively low TILs would require additional strategies to increase TILs prior to immune checkpoint blockade . Cancer vaccine can activate and expand tumor-specific CD8+ T cells but itself usually yields limited success in controlling cancer progression . Vaccine priming before or concurrent with one or several immune checkpoint blockade may potentiate the effector T-cell functions and finally translate into long-term disease control of mBC. 


\section{Conclusions and future directions}

Advances in cancer genomics have identified a large number of potential therapeutic targets, many of which have been studied extensively in preclinical and clinical models. Better classification of breast cancer subtypes and in depth characterization of druggable signaling pathways using new biotechnologies like next-generation sequencing (NGS) will enable selection of the most appropriate drugs to target specific genomic alterations. Mutations of BRCA, PIK3CA, AKT1, etc., as well as deregulated signaling such as the FGF and AR pathways, provide promising targets to individualize therapy in metastatic breast cancer. Tumor-intrinsic targeted therapies are likely to yield higher specificity and less toxicity, but may develop drug resistance as the treatment continues. This could be due to secondary mutations that abrogate contact points for drug binding, and/or activation of alternative compensatory signaling mechanisms . On the other hand, the stroma-centric targeting approach could elicit a broader impact against cancerous cells. This strategy has been proved successful in other tumor types such as melanoma, and has also demonstrated promising preliminary results in a subset of mBC patients. Targeting the tumor-promoting elements of the TME and harnessing host immune mechanisms to eradicate cancer cells represent an emerging treatment paradigm. However, while the signaling molecules between the tumor and immune-suppressive stromal cells are potential drug targets, the similarities between tumor-associated stroma and normal stromal cells may potentially cause severe adverse effects .

Our knowledge of breast cancer metastasis has advanced significantly in recent years, with particular emphasis on an integrated understanding of the tumor and its associated microenvironment. Most of current clinical studies are still at early stages of evaluating single or double agent toxicity and efficacy. As a step forward, it is important to start combining drugs using biologically informed translational studies to guide trial design and improve patient outcomes. Although most current approaches of precision medicine aim at 
targeting driver events, additional applications such as identification of DNA repair deficiencies and mechanisms of immune suppression could be developed in the future. The ultimate goal is to attack the tumor cells as well as the TME, and at the same time preserve the normal function of organs not involved. Rational combinations of surgery/ radiotherapy/ cytotoxic chemotherapy, with tumor-intrinsic and/or stroma-centric targeted therapies, are likely to improve the treatment efficacy without causing severe toxic effects. 


\section{Figure legends:}

Figure 1. Therapeutic candidates targeting tumor-intrinsic pathways of mBC. This schematic diagram highlights several tumor-intrinsic pathways and the therapeutic agents currently available or being developed to target them.

Figure 2. Therapeutic candidates targeting tumor-stromal interactions and enhancing host immune response of $\mathbf{m B C}$. This schematic diagram illustrates severeal key stromal cell populations important for regulating the growth of $\mathrm{mBC}$, as well as therapeutic agents available or being developed to target the molecular pathways that mediate tumor-stromal interactions. 


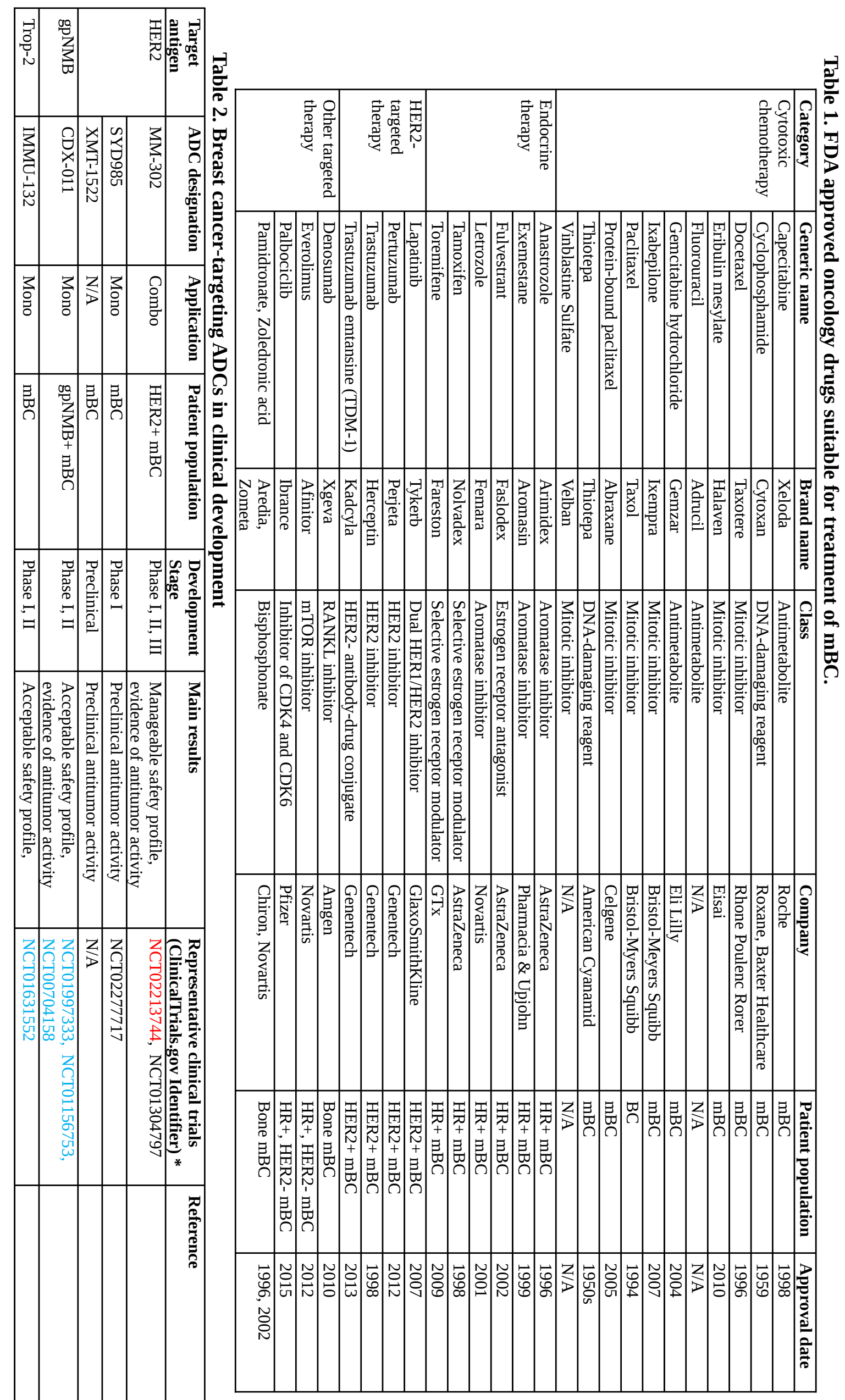




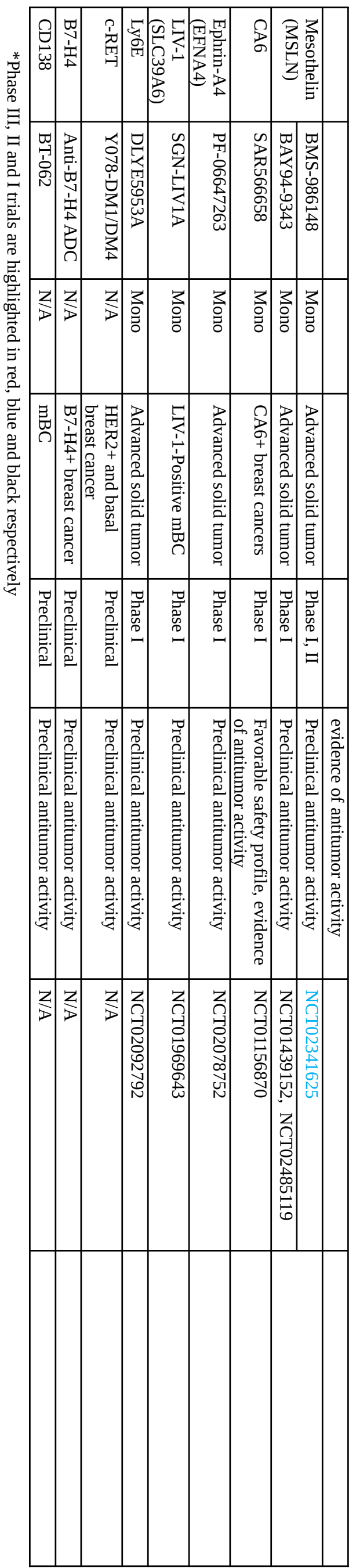




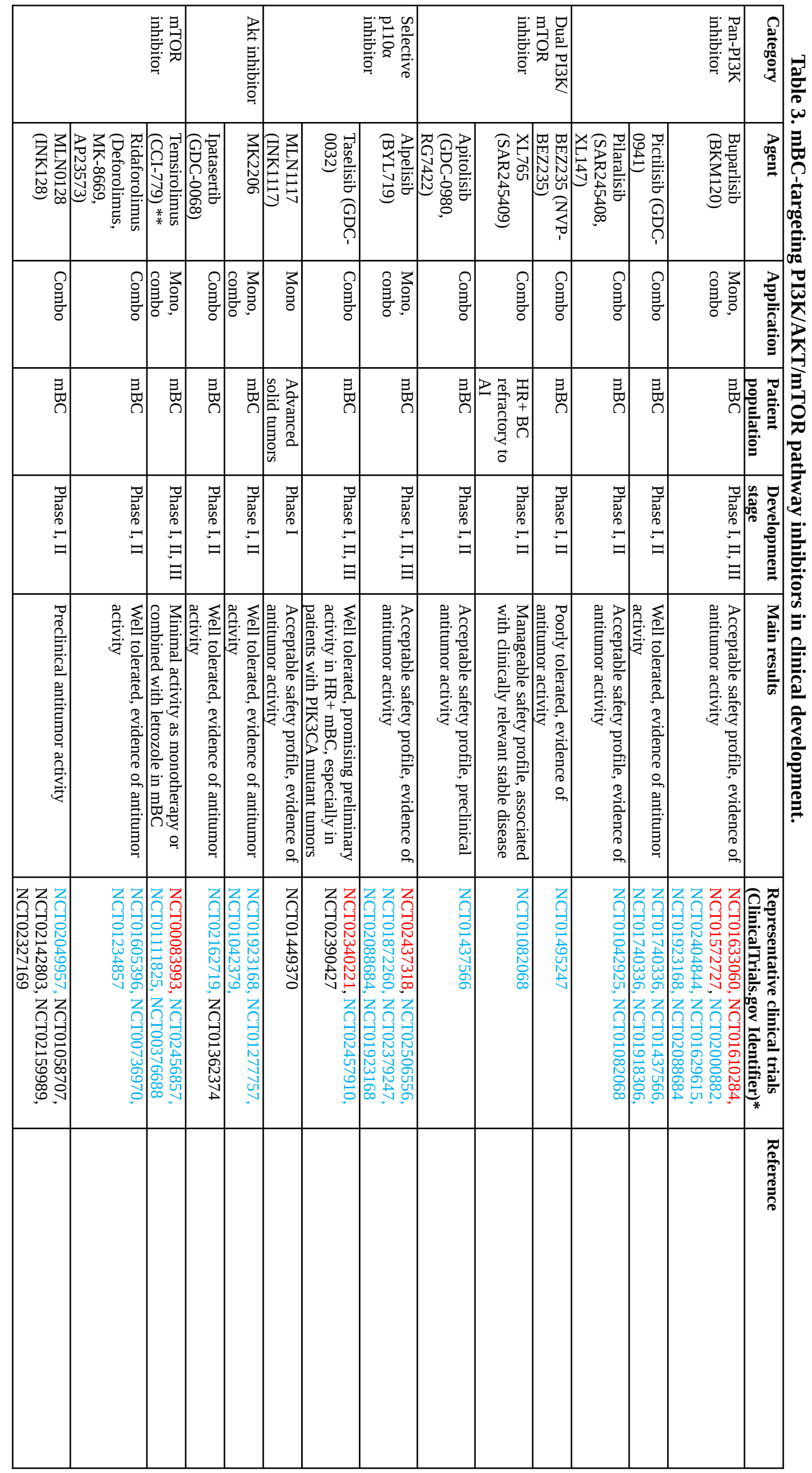




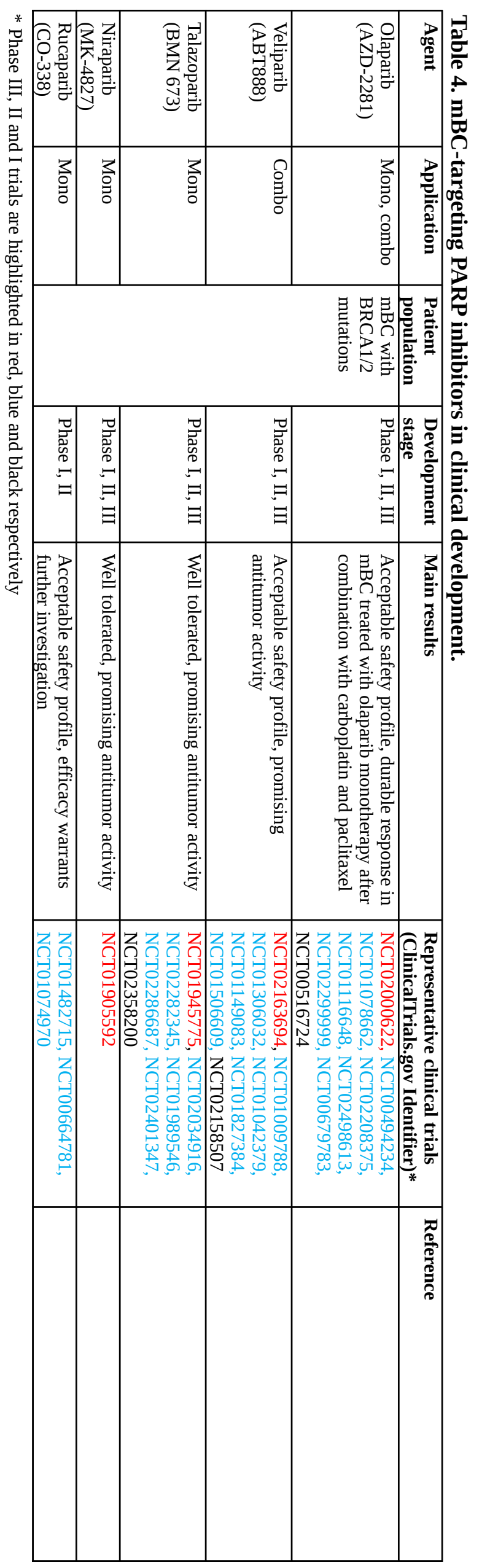




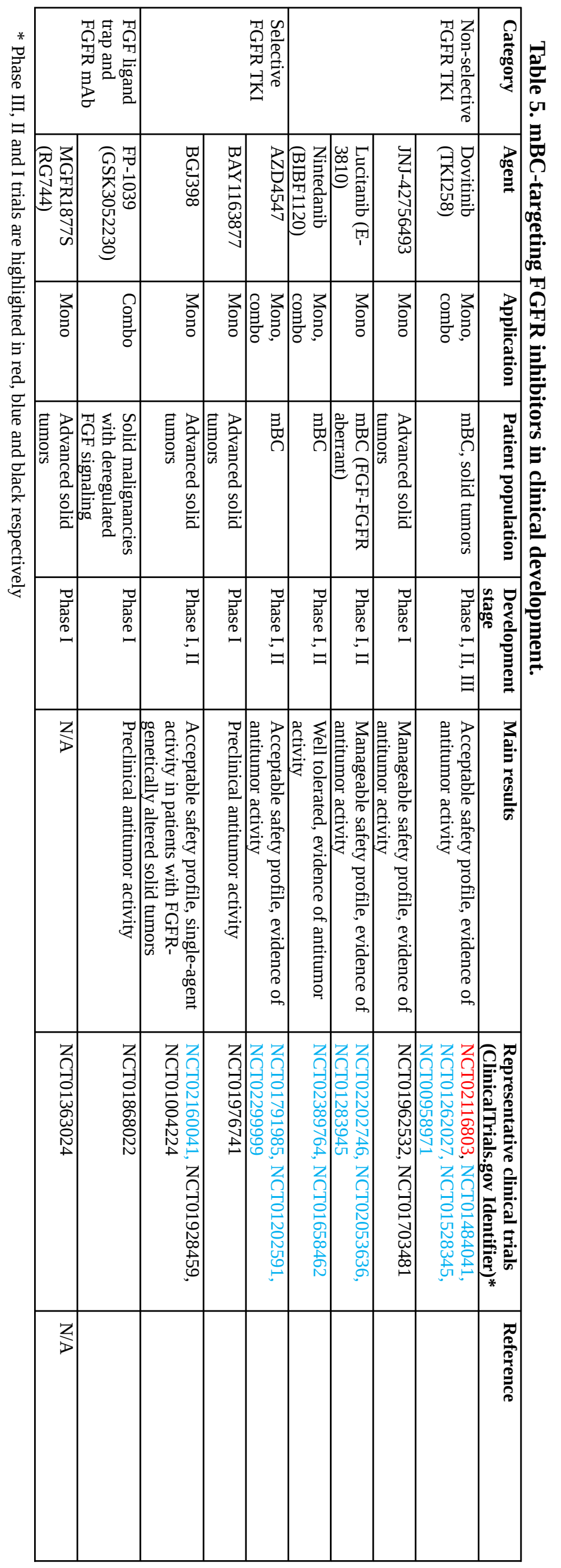




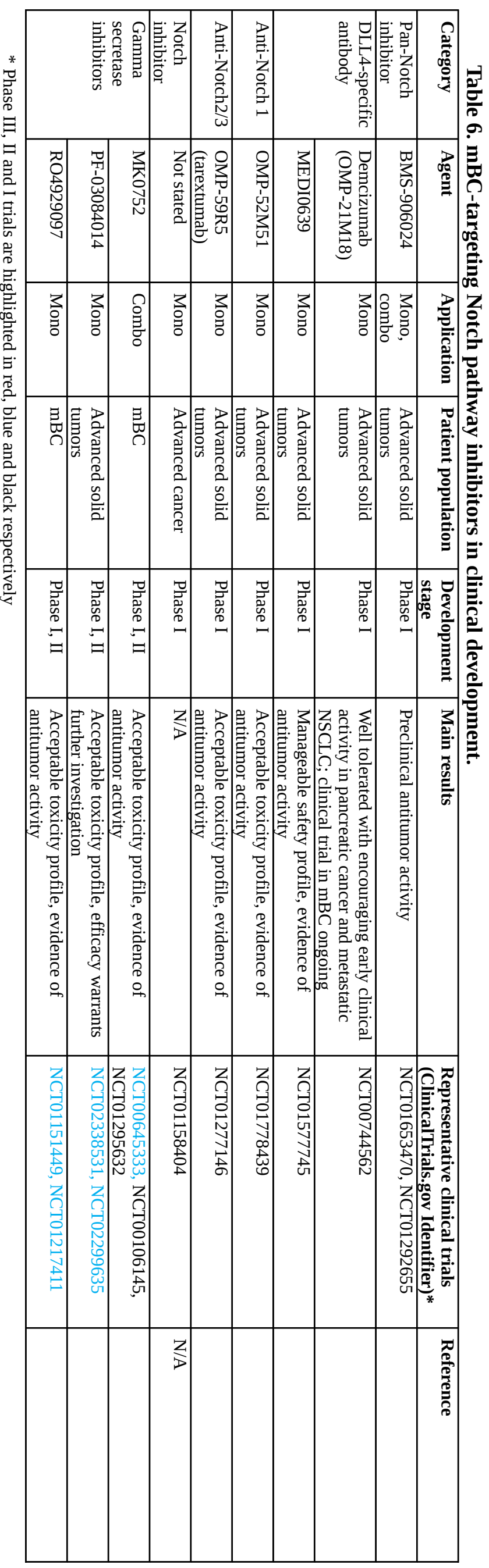




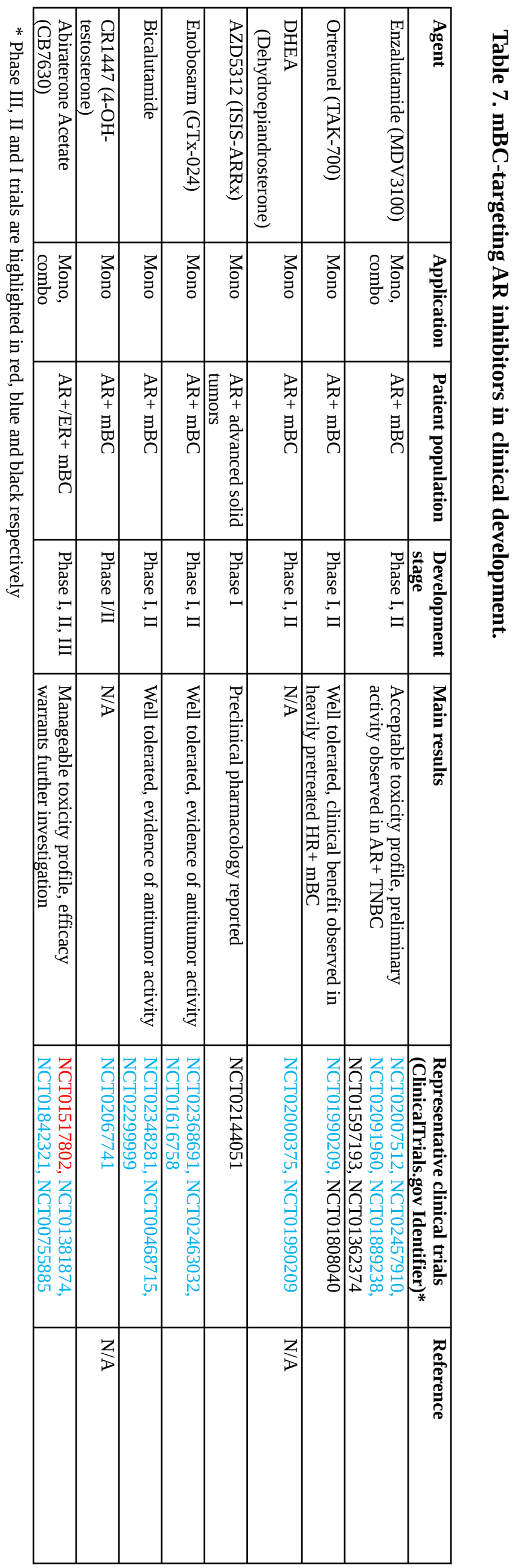




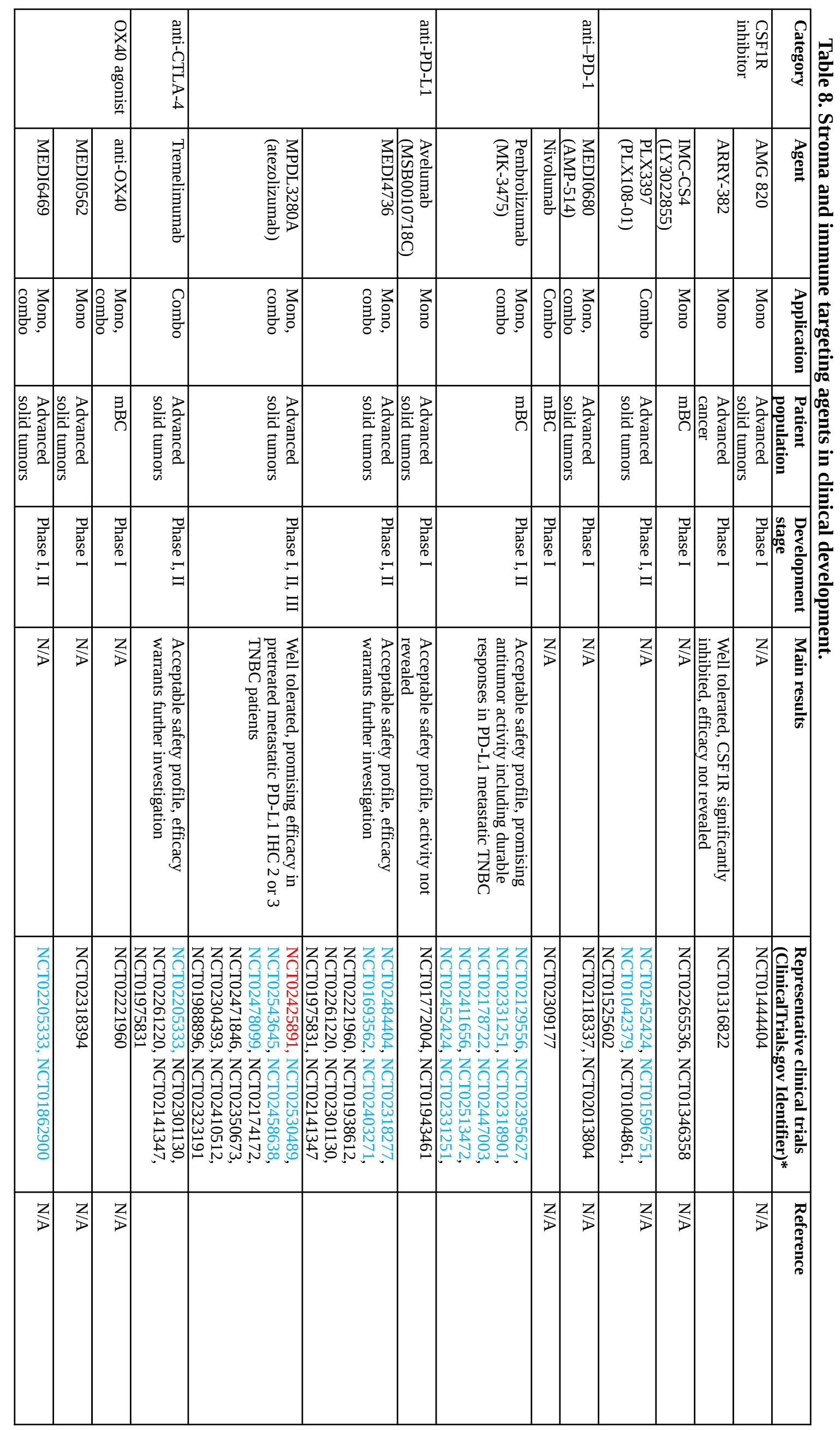




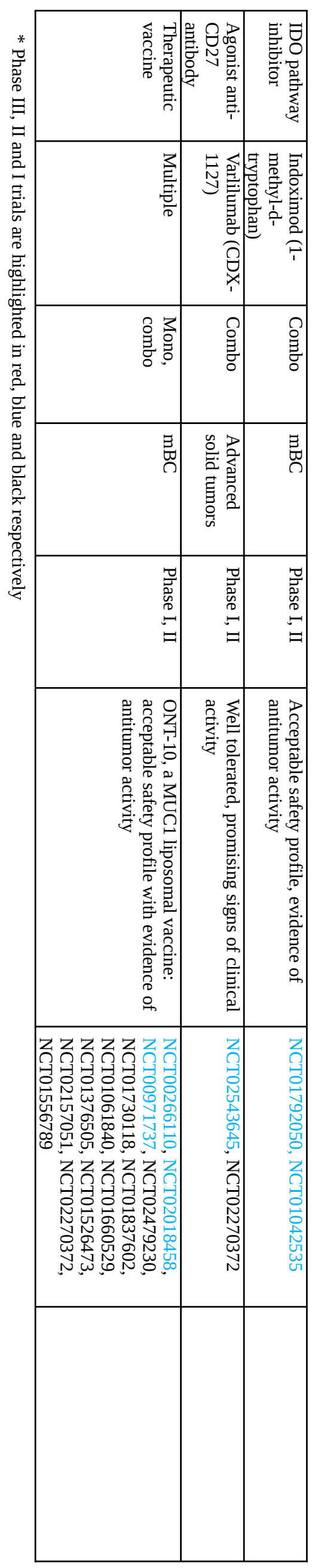




\section{Acknowledgement}

We thank the members of our laboratories for helpful discussions and M. Esposito, W. Lu, Y. Wei, and H.A. Smith for critical reading of the manuscript. We also apologize to the many investigators whose important studies could not be cited directly here owing to space limitations. The work was supported by Howard Hughes Medical Institute International Student Research Fellowship to Z.L. and grants from the Brewster Foundation, the Breast Cancer Research Foundation and the U. S. Department of Defense (BC123187) to Y.K. 


\section{References}

Agoff, S.N., Swanson, P.E., Linden, H., Hawes, S.E., and Lawton, T.J. (2003). Androgen receptor expression in estrogen receptor-negative breast cancer. Immunohistochemical, clinical, and prognostic associations. Am. J. Clin. Pathol. 120, 725-731.

Ahmad, A. (2013). Pathways to breast cancer recurrence. ISRN Oncol. 2013, 290568.

Ahnert, J.R., Schuler, M.H., Machiels, J.H., Hess, D., Paz-Ares, L., Awada, A., et al. (2014). Phase lb study of BEZ235 plus either paclitaxel (PTX) in advanced solid tumors (aST) or PTX plus trastuzumab (TZ) in HER2+ breast cancer (BC). J Clin Oncol 32:5s, suppl; abstr 621^.

Aksamitiene, E., Kiyatkin, A., and Kholodenko, B.N. (2012). Cross-talk between mitogenic Ras/MAPK and survival PI3K/Akt pathways: a fine balance. Biochem. Soc. Trans. 40, 139-146.

Alley, S.C., Okeley, N.M., and Senter, P.D. (2010). Antibody-drug conjugates: targeted drug delivery for cancer. Curr. Opin. Chem. Biol. 14, 529-537.

American Cancer Society (2013). Breast Cancer Facts \& Figures 2013-2014. Atlanta: American Cancer Society, Inc.

Anastas, J.N., and Moon, R.T. (2013). WNT signalling pathways as therapeutic targets in cancer. Nat. Rev. Cancer 13, 11-26.

Andersson, E.R., and Lendahl, U. (2014). Therapeutic modulation of Notch signalling--are we there yet? Nat. Rev. Drug Discov. 13, 357-378.

Andre, F., Bachelot, T.D., Campone, M., Dalenc, F., Perez-Garcia, J.M., Hurvitz, S.A., et al. (2011). A multicenter, open-label phase II trial of dovitinib, an FGFR1 inhibitor, in FGFR1 amplified and non-amplified metastatic breast cancer. ASCO Meet. Abstr. 29, 508.

Andre, F., Ranson, M., Dean, E., Varga, A., van der Noll, R., Stockman, P.K., et al. (2014). Abstract LB-145: Results of a phase I study of AZD4547, an inhibitor of fibroblast growth factor receptor (FGFR), in patients with advanced solid tumors . Cancer Res. 73, LB - 145 - LB - 145.

André, F., Bachelot, T., Campone, M., Dalenc, F., Perez-Garcia, J.M., Hurvitz, S.A., et al. (2013). Targeting FGFR with dovitinib (TKI258): preclinical and clinical data in breast cancer. Clin. Cancer Res. 19, 36933702.

Andrei, A.-Z., Hall, A., Smith, A.L., Bascuñana, C., Malina, A., Connor, A., et al. (2015). Increased in vitro and in vivo sensitivity of BRCA2-associated pancreatic cancer to the poly(ADP-ribose) polymerase-1/2 inhibitor BMN 673. Cancer Lett. 364, 8-16. 
Armulik, A., Abramsson, A., and Betsholtz, C. (2005). Endothelial/pericyte interactions. Circ. Res. 97, 512523.

Ashworth, A. (2008). A synthetic lethal therapeutic approach: poly(ADP) ribose polymerase inhibitors for the treatment of cancers deficient in DNA double-strand break repair. J. Clin. Oncol. 26, 3785-3790.

Asundi, J., Crocker, L., Tremayne, J., Chang, P., Sakanaka, C., Tanguay, J., et al. (2015). An Antibody-Drug Conjugate Directed against Lymphocyte Antigen 6 Complex, Locus E (LY6E) Provides Robust Tumor Killing in a Wide Range of Solid Tumor Malignancies. Clin. Cancer Res. 21, 3252-3262.

Augsten, M. (2014). Cancer-associated fibroblasts as another polarized cell type of the tumor microenvironment. Front. Oncol. 4, 62.

Baay, M., Brouwer, A., Pauwels, P., Peeters, M., and Lardon, F. (2011). Tumor cells and tumor-associated macrophages: secreted proteins as potential targets for therapy. Clin. Dev. Immunol. 2011, 565187.

Baginska, J., Viry, E., Paggetti, J., Medves, S., Berchem, G., Moussay, E., et al. (2013). The critical role of the tumor microenvironment in shaping natural killer cell-mediated anti-tumor immunity. Front. Immunol. 4, 490.

Balic, M., Lin, H., Young, L., Hawes, D., Giuliano, A., and McNamara, G., et al (2006). Most early disseminated cancer cells detected in bone marrow of breast cancer patients have a putative breast cancer stem cell phenotype. Clin. Cancer Res. 12, 5615-5621.

Balsamo, M., Scordamaglia, F., Pietra, G., Manzini, C., Cantoni, C., Boitano, M., et al. (2009). Melanomaassociated fibroblasts modulate NK cell phenotype and antitumor cytotoxicity. Proc. Natl. Acad. Sci. U. S. A. 106, 20847-20852.

Baron, R., Ferrari, S., and Russell, R.G.G. (2011). Denosumab and bisphosphonates: different mechanisms of action and effects. Bone 48, 677-692.

Barton, V., D’Amato, N., and Richer, J. (2014). Abstract A047: Targeting androgen receptor decreases proliferation of triple-negative breast cancer. Mol. Cancer Res. 11, A047-A047.

Barton, V.N., D’Amato, N.C., Gordon, M.A., Lind, H.T., Spoelstra, N.S., Babbs, B.L., et al. (2015). Multiple molecular subtypes of triple-negative breast cancer critically rely on androgen receptor and respond to enzalutamide in vivo. Mol. Cancer Ther. 14, 769-778.

Bellone, M., and Calcinotto, A. (2013). Ways to enhance lymphocyte trafficking into tumors and fitness of tumor infiltrating lymphocytes. Front. Oncol. 3, 231.

Bendell, J., Saleh, M., Rose, A.A.N., Siegel, P.M., Hart, L., Sirpal, S., et al. (2014a). Phase I/II study of the antibody-drug conjugate glembatumumab vedotin in patients with locally advanced or metastatic breast cancer. J. Clin. Oncol. 32, 3619-3625. 
Bendell, J.C., Tolcher, A.W., Jones, S.F., Beeram, M., Infante, J.R., Larsen, P., et al. (2014b). Abstract A252: A phase 1 study of ARRY-382, an oral inhibitor of colony-stimulating factor-1 receptor (CSF1R), in patients with advanced or metastatic cancers. Mol. Cancer Ther. 12, A252-A252.

Bergstrom, D.A., Bodyak, N., Yurkovetskiy, A., Park, P.U., DeVit, M., Yin, M., et al. (2015). Abstract LB-231: A novel, highly potent HER2-targeted antibody-drug conjugate (ADC) for the treatment of low HER2expressing tumors and combination with trastuzumab-based regimens in HER2-driven tumors. Cancer Res. 75, LB - 231 - LB - 231.

Berns, K., Horlings, H.M., Hennessy, B.T., Madiredjo, M., Hijmans, E.M., Beelen, K., et al. (2007). A functional genetic approach identifies the PI3K pathway as a major determinant of trastuzumab resistance in breast cancer. Cancer Cell 12, 395-402.

Boni, V., Rixe, O., Rasco, D., Gomez-Roca, C., Calvo, E., Morris, J.C., et al. (2014). Abstract A73: A Phase I first-in-human (FIH) study of SAR566658, an anti CA6-antibody drug conjugate (ADC), in patients (Pts) with CA6-positive advanced solid tumors (STs) (NCT01156870). Mol. Cancer Ther. 12, A73-A73.

Borcherding, N., Ameka, M., Kolb, R., Xie, Q., and Zhang, W. (2014a). Abstract 2083: WNT5a/ROR1 axis in triple-negative breast cancer progression and potential therapy. Cancer Res. 74, 2083-2083.

Borcherding, N., Kusner, D., Liu, G.-H., and Zhang, W. (2014b). ROR1, an embryonic protein with an emerging role in cancer biology. Protein Cell 5, 496-502.

Bosco, J.L.F., Lash, T.L., Prout, M.N., Buist, D.S.M., Geiger, A.M., Haque, R., et al. (2009). Breast cancer recurrence in older women five to ten years after diagnosis. Cancer Epidemiol. Biomarkers Prev. 18, 29792983.

Bose, S., Chandran, S., Mirocha, J.M., and Bose, N. (2006). The Akt pathway in human breast cancer: a tissue-array-based analysis. Mod. Pathol. 19, 238-245.

Brana, I., Berger, R., Golan, T., Haluska, P., Edenfield, J., Fiorica, J., et al. (2014). A parallel-arm phase I trial of the humanised anti-IGF-1R antibody dalotuzumab in combination with the AKT inhibitor MK-2206, the mTOR inhibitor ridaforolimus, or the NOTCH inhibitor MK-0752, in patients with advanced solid tumours. Br. J. Cancer 111, 1932-1944.

Buisseret, L., Specht, J., Dees, E.C., Berger, R., Gupta, S., Geva, R., et al. (2015). 14P * KEYNOTE-012: A phase Ib study of pembrolizumab (MK-3475) in patients (pts) with metastatic triple-negative breast cancer (mTNBC). Ann. Oncol. 26, iii6-iii6.

Bullock, T., McClintic, H., Jeong, S., Smith, K., Olson, W., Ramakrishna, V., et al. (2014). Immune correlates of Varlilumab treated cancer patients are consistent with CD27 costimulatory activity. J. Immunother. Cancer 2, P100.

Burger, H.G. (2002). Androgen production in women. Fertil. Steril. 77 Suppl 4, S3-S5. 
Butler, J.M., Kobayashi, H., and Rafii, S. (2010). Instructive role of the vascular niche in promoting tumour growth and tissue repair by angiocrine factors. Nat. Rev. Cancer 10, 138-146.

Campbell, M.J., Scott, J., Maecker, H.T., Park, J.W., and Esserman, L.J. (2005). Immune dysfunction and micrometastases in women with breast cancer. Breast Cancer Res. Treat. 91, 163-171.

Cancilla, B., Tam, R., Zhang, C., Anderson, S., Lewicki, J., Hoey, T., et al. (2015). Abstract 1549:

Development and validation of a biomarker for prospective selection of Notch1 activation in patients with certain advanced solid tumors in a first-in-human phase1 study of the cancer stem cell targeting antibody OMP-52M51 (anti-Notch1). Cancer Res. 75, 1549-1549.

Carmeliet, P. (2005). VEGF as a key mediator of angiogenesis in cancer. Oncology 69 Suppl 3, 4-10.

Carracedo, A., and Pandolfi, P.P. (2008). The PTEN-PI3K pathway: of feedbacks and cross-talks. Oncogene 27, 5527-5541.

Carvalho, I., Milanezi, F., Martins, A., Reis, R.M., and Schmitt, F. (2005). Overexpression of platelet-derived growth factor receptor alpha in breast cancer is associated with tumour progression. Breast Cancer Res. 7 , R788-R795.

Cassier, P.A., Italiano, A., Gomez-Roca, C.A., Le Tourneau, C., Toulmonde, M., Cannarile, M.A., et al. (2015). CSF1R inhibition with emactuzumab in locally advanced diffuse-type tenosynovial giant cell tumours of the soft tissue: a dose-escalation and dose-expansion phase 1 study. Lancet. Oncol. 16, 949-956.

Cavazzoni, A., Bonelli, M.A., Fumarola, C., La Monica, S., Airoud, K., Bertoni, R., et al. (2012). Overcoming acquired resistance to letrozole by targeting the PI3K/AKT/mTOR pathway in breast cancer cell clones.

Cancer Lett. 323, 77-87.

Chaturvedi, P., Gilkes, D.M., Wong, C.C.L., Luo, W., Zhang, H., Wei, H., et al. (2013). Hypoxia-inducible factor-dependent breast cancer-mesenchymal stem cell bidirectional signaling promotes metastasis. J. Clin. Invest. 123, 189-205.

Chen, M., Ouyang, H., Zhou, S., Li, J., and Ye, Y. (2014). PLGA-nanoparticle mediated delivery of anti-OX40 monoclonal antibody enhances anti-tumor cytotoxic T cell responses. Cell. Immunol. 287, 91-99.

Choi, A.-R., Park, J.-R., Kim, R.-J., Kim, S.-R., Cho, S.-D., Jung, J.-Y., et al. (2012). Inhibition of Wnt1 expression reduces the enrichment of cancer stem cells in a mouse model of breast cancer. Biochem. Biophys. Res. Commun. 425, 436-442.

Chuang, H.-C., Kapuriya, N., Kulp, S.K., Chen, C.-S., and Shapiro, C.L. (2012). Differential anti-proliferative activities of poly(ADP-ribose) polymerase (PARP) inhibitors in triple-negative breast cancer cells. Breast Cancer Res. Treat. 134, 649-659.

Cimino-Mathews, A., Foote, J.B., and Emens, L.A. (2015). Immune targeting in breast cancer. Oncology (Williston Park). 29, 375-385. 
Cleator, S., Heller, W., and Coombes, R.C. (2007). Triple-negative breast cancer: therapeutic options. Lancet. Oncol. 8, 235-244.

Cochrane, D.R., Bernales, S., Jacobsen, B.M., Cittelly, D.M., Howe, E.N., D’Amato, N.C., et al. (2014). Role of the androgen receptor in breast cancer and preclinical analysis of enzalutamide. Breast Cancer Res. 16, R7.

Coleman, R.E. (2006). Clinical features of metastatic bone disease and risk of skeletal morbidity. Clin. Cancer Res. 12, 6243s - 6249s.

Coley, H.M. (2008). Mechanisms and strategies to overcome chemotherapy resistance in metastatic breast cancer. Cancer Treat. Rev. 34, 378-390.

Coltrera, M.D., Wang, J., Porter, P.L., and Gown, A.M. (1995). Expression of platelet-derived growth factor B-chain and the platelet-derived growth factor receptor beta subunit in human breast tissue and breast carcinoma. Cancer Res. 55, 2703-2708.

Di Cosimo, S., Sathyanarayanan, S., Bendell, J.C., Cervantes, A., Stein, M.N., Braña, I., et al. (2015). Combination of the mTOR inhibitor ridaforolimus and the anti-IGF1R monoclonal antibody dalotuzumab: preclinical characterization and phase I clinical trial. Clin. Cancer Res. 21, 49-59.

Cox, T.R., Rumney, R.M.H., Schoof, E.M., Perryman, L., Høye, A.M., Agrawal, A., et al. (2015). The hypoxic cancer secretome induces pre-metastatic bone lesions through lysyl oxidase. Nature 522, 106-110.

Creighton, C.J., Fu, X., Hennessy, B.T., Casa, A.J., Zhang, Y., Gonzalez-Angulo, A.M., et al. (2010). Proteomic and transcriptomic profiling reveals a link between the PI3K pathway and lower estrogen-receptor (ER) levels and activity in ER+ breast cancer. Breast Cancer Res. 12, R40.

Criscitiello, C., Azim, H.A., Schouten, P.C., Linn, S.C., and Sotiriou, C. (2012). Understanding the biology of triple-negative breast cancer. Ann. Oncol. 23 Suppl 6, vi13-vi18.

Cuiffo, B.G., Campagne, A., Bell, G.W., Lembo, A., Orso, F., Lien, E.C., et al. (2014). MSC-regulated microRNAs converge on the transcription factor FOXP2 and promote breast cancer metastasis. Cell Stem Cell 15, 762-774.

Curti, B.D., Kovacsovics-Bankowski, M., Morris, N., Walker, E., Chisholm, L., Floyd, K., et al. (2013). OX40 is a potent immune-stimulating target in late-stage cancer patients. Cancer Res. 73, 7189-7198.

Dalotto-Moreno, T., Croci, D.O., Cerliani, J.P., Martinez-Allo, V.C., Dergan-Dylon, S., Méndez-Huergo, S.P., et al. (2013). Targeting galectin-1 overcomes breast cancer-associated immunosuppression and prevents metastatic disease. Cancer Res. 73, 1107-1117.

Dalton, J.T., Barnette, K.G., Bohl, C.E., Hancock, M.L., Rodriguez, D., Dodson, S.T., et al. (2011). The selective androgen receptor modulator GTx-024 (enobosarm) improves lean body mass and physical function in healthy elderly men and postmenopausal women: results of a double-blind, placebo-controlled phase II trial. J. Cachexia. Sarcopenia Muscle 2, 153-161. 
Damelin, M., Bankovich, A., Park, A., Aguilar, J., Anderson, W., Santaguida, M., et al. (2015). Anti-EFNA4 Calicheamicin Conjugates Effectively Target Triple-Negative Breast and Ovarian Tumor-Initiating Cells to Result in Sustained Tumor Regressions. Clin. Cancer Res.

David, M.-P., Van Herck, K., Hardt, K., Tibaldi, F., Dubin, G., Descamps, D., et al. (2009). Long-term persistence of anti-HPV-16 and -18 antibodies induced by vaccination with the AS04-adjuvanted cervical cancer vaccine: modeling of sustained antibody responses. Gynecol. Oncol. 115, S1-S6.

Davies, B.R., Thomason, A., Ellston, R., Campbell, H., D’Cruz, C., Mazzola, A.M., et al. (2014). 457 Preclinical pharmacology of AZD5312, a generation 2.5 antisense oligonucletotide targeting the androgen receptor with differentiated activity from enzalutamide. Eur. J. Cancer 50, 150.

Davies, C., Pan, H., Godwin, J., Gray, R., Arriagada, R., Raina, V., et al. (2013). Long-term effects of continuing adjuvant tamoxifen to 10 years versus stopping at 5 years after diagnosis of oestrogen receptorpositive breast cancer: ATLAS, a randomised trial. Lancet 381, 805-816.

Davis, S.L., LoRusso, P., Xu, L., Kapoun, A.M., Dupont, J., Munster, P., et al. (2014). Abstract B48: A first-inhuman Phase I study of the novel cancer stem cell (CSC) targeting antibody OMP-52M51 (anti-Notch1) administered intravenously to patients with certain advanced solid tumors. Mol. Cancer Ther. 12, B48-B48.

De, P.K., Sun, Y., Carlson, J.H., Lin, X., Dey, N., and Leyland-Jones, B. (2015). Abstract 1940: Dual inhibition of mTORC1/C2 and HER2 results in maximal antitumor efficacy in preclinical model of HER2+ breast cancer resistant to trastuzumab therapy. Cancer Res. 75, 1940-1940.

DeNardo, D.G., and Coussens, L.M. (2007). Inflammation and breast cancer. Balancing immune response: crosstalk between adaptive and innate immune cells during breast cancer progression. Breast Cancer Res. 9, 212.

DeNardo, D.G., Brennan, D.J., Rexhepaj, E., Ruffell, B., Shiao, S.L., Madden, S.F., et al. (2011). Leukocyte complexity predicts breast cancer survival and functionally regulates response to chemotherapy. Cancer Discov. 1, 54-67.

Denkert, C., Loibl, S., Noske, A., Roller, M., Müller, B.M., Komor, M., et al. (2010). Tumor-associated lymphocytes as an independent predictor of response to neoadjuvant chemotherapy in breast cancer. J. Clin. Oncol. 28, 105-113.

Dent, R.A., Lindeman, G.J., Clemons, M., Wildiers, H., Chan, A., McCarthy, N.J., et al. (2013). Phase I trial of the oral PARP inhibitor olaparib in combination with paclitaxel for first- or second-line treatment of patients with metastatic triple-negative breast cancer. Breast Cancer Res. 15, R88.

Dieci, M. V, Mathieu, M.C., Guarneri, V., Conte, P., Delaloge, S., Andre, F., et al. (2015). Prognostic and predictive value of tumor-infiltrating lymphocytes in two phase III randomized adjuvant breast cancer trials. Ann. Oncol. 26, 1698-1704. 
Dienstmann, R., Bahleda, R., Adamo, B., Rodon, J., Varga, A., Gazzah, A., et al. (2014). Abstract CT325: First in human study of JNJ-42756493, a potent pan fibroblast growth factor receptor (FGFR) inhibitor in patients with advanced solid tumors. Cancer Res. 74, CT325-CT325.

DiMeo, T.A., Anderson, K., Phadke, P., Fan, C., Feng, C., Perou, C.M., et al. (2009). A novel lung metastasis signature links Wnt signaling with cancer cell self-renewal and epithelial-mesenchymal transition in basal-like breast cancer. Cancer Res. 69, 5364-5373.

Dokter, W., Ubink, R., van der Lee, M., van der Vleuten, M., van Achterberg, T., Jacobs, D., et al. (2014). Preclinical profile of the HER2-targeting ADC SYD983/SYD985: introduction of a new duocarmycin-based linker-drug platform. Mol. Cancer Ther. 13, 2618-2629.

Drake, M.T., Clarke, B.L., and Khosla, S. (2008). Bisphosphonates: mechanism of action and role in clinical practice. Mayo Clin. Proc. 83, 1032-1045.

Drost, R., and Jonkers, J. (2014). Opportunities and hurdles in the treatment of BRCA1-related breast cancer. Oncogene 33, 3753-3763.

Durmus, S., Sparidans, R.W., van Esch, A., Wagenaar, E., Beijnen, J.H., and Schinkel, A.H. (2015). Breast cancer resistance protein (BCRP/ABCG2) and P-glycoprotein (P-GP/ABCB1) restrict oral availability and brain accumulation of the PARP inhibitor rucaparib (AG-014699). Pharm. Res. 32, 37-46.

Dushyanthen, S., Beavis, P.A., Savas, P., Teo, Z.L., Zhou, C., Mansour, M., et al. (2015). Relevance of tumorinfiltrating lymphocytes in breast cancer. BMC Med. 13, 202.

Dwadasi, S., Tong, Y., Walsh, T., Danso, M.A., Ma, C.X., Silverman, P., et al. (2014). Cisplatin with or without rucaparib after preoperative chemotherapy in patients with triple-negative breast cancer (TNBC): Hoosier Oncology Group BRE09-146. J Clin Oncol 32:5s, suppl; abstr 1019.

Elgersma, R.C., Coumans, R.G.E., Huijbregts, T., Menge, W.M.P.B., Joosten, J.A.F., Spijker, H.J., et al. (2015). Design, Synthesis, and Evaluation of Linker-Duocarmycin Payloads: Toward Selection of HER2Targeting Antibody-Drug Conjugate SYD985. Mol. Pharm. 12, 1813-1835.

Emens, L.A., Braiteh, F.S., Cassier, P., Delord, J.-P., Eder, J.P., Fasso, M., et al. (2015). Abstract 2859: Inhibition of PD-L1 by MPDL3280A leads to clinical activity in patients with metastatic triple-negative breast cancer (TNBC). Cancer Res. 75, 2859-2859.

Erler, J.T., Bennewith, K.L., Nicolau, M., Dornhöfer, N., Kong, C., Le, Q.-T., et al. (2006). Lysyl oxidase is essential for hypoxia-induced metastasis. Nature 440, 1222-1226.

Erler, J.T., Bennewith, K.L., Cox, T.R., Lang, G., Bird, D., Koong, A., et al. (2009). Hypoxia-induced lysyl oxidase is a critical mediator of bone marrow cell recruitment to form the premetastatic niche. Cancer Cell 15, 35-44. 
Esposito, M., and Kang, Y. (2014). Targeting tumor-stromal interactions in bone metastasis. Pharmacol. Ther. 141, 222-233.

Falchook, G.S., Dowlati, A., Naing, A., Gribbin, M.J., Jenkins, D.W., Chang, L.L., et al. (2015). Phase I study of MEDI0639 in patients with advanced solid tumors. J Clin Oncol 33, suppl; abstr 3024.

Farmer, P., Bonnefoi, H., Becette, V., Tubiana-Hulin, M., Fumoleau, P., Larsimont, D., et al. (2005). Identification of molecular apocrine breast tumours by microarray analysis. Oncogene 24, 4660-4671.

Farnie, G., and Clarke, R.B. (2007). Mammary Stem Cells and Breast Cancer-Role of Notch Signalling. Stem Cell Rev. 3, 169-175.

Fedele, C.G., Ooms, L.M., Ho, M., Vieusseux, J., O’Toole, S.A., Millar, E.K., et al. (2010). Inositol polyphosphate 4-phosphatase II regulates PI3K/Akt signaling and is lost in human basal-like breast cancers. Proc. Natl. Acad. Sci. U. S. A. 107, 22231-22236.

Feng, F.Y., de Bono, J.S., Rubin, M.A., and Knudsen, K.E. (2015). Chromatin to Clinic: The Molecular Rationale for PARP1 Inhibitor Function. Mol. Cell 58, 925-934.

Finak, G., Bertos, N., Pepin, F., Sadekova, S., Souleimanova, M., Zhao, H., et al. (2008). Stromal gene expression predicts clinical outcome in breast cancer. Nat. Med. 14, 518-527.

Fleisch, H. (1998). Bisphosphonates: mechanisms of action. Endocr. Rev. 19, 80-100.

Fleming, G.F., Ma, C.X., Huo, D., Sattar, H., Tretiakova, M., Lin, L., et al. (2012). Phase II trial of temsirolimus in patients with metastatic breast cancer. Breast Cancer Res. Treat. 136, 355-363.

Fresno Vara, J.A., Casado, E., de Castro, J., Cejas, P., Belda-Iniesta, C., and González-Barón, M. (2004). PI3K/Akt signalling pathway and cancer. Cancer Treat. Rev. 30, 193-204.

Fruman, D.A., and Rommel, C. (2014). PI3K and cancer: lessons, challenges and opportunities. Nat. Rev. Drug Discov. 13, 140-156.

Gabrilovich, D.I., and Nagaraj, S. (2009). Myeloid-derived suppressor cells as regulators of the immune system. Nat. Rev. Immunol. 9, 162-174.

Gao, M.-Q., Kim, B.G., Kang, S., Choi, Y.P., Yoon, J.-H., and Cho, N.H. (2013). Human breast cancerassociated fibroblasts enhance cancer cell proliferation through increased TGF- $\alpha$ cleavage by ADAM17. Cancer Lett. 336, 240-246.

Garay, J.P., and Park, B.H. (2012). Androgen receptor as a targeted therapy for breast cancer. Am. J. Cancer Res. 2, 434-445.

Garraway, L.A., and Jänne, P.A. (2012). Circumventing cancer drug resistance in the era of personalized medicine. Cancer Discov. 2, 214-226. 
Gavai, A. V, Quesnelle, C., Norris, D., Han, W.-C., Gill, P., Shan, W., et al. (2015). Discovery of Clinical Candidate BMS-906024: A Potent Pan-Notch Inhibitor for the Treatment of Leukemia and Solid Tumors. ACS Med. Chem. Lett. 6, 523-527.

Gelmann, E.P. (2002). Molecular biology of the androgen receptor. J. Clin. Oncol. 20, 3001-3015.

Gelmon, K.A., Tischkowitz, M., Mackay, H., Swenerton, K., Robidoux, A., Tonkin, K., et al. (2011). Olaparib in patients with recurrent high-grade serous or poorly differentiated ovarian carcinoma or triple-negative breast cancer: a phase 2, multicentre, open-label, non-randomised study. Lancet. Oncol. 12, 852-861.

Geretti, E., Leonard, S.C., Dumont, N., Lee, H., Zheng, J., De Souza, R., et al. (2015). CyclophosphamideMediated Tumor Priming for Enhanced Delivery and Antitumor Activity of HER2-Targeted Liposomal Doxorubicin (MM-302). Mol. Cancer Ther. 14, 2060-2071.

Geuna, E., Milani, A., Martinello, R., Aversa, C., Valabrega, G., Scaltriti, M., et al. (2015). Buparlisib , an oral pan-PI3K inhibitor for the treatment of breast cancer. Expert Opin. Investig. Drugs 24, 421-431.

Gewinner, C., Wang, Z.C., Richardson, A., Teruya-Feldstein, J., Etemadmoghadam, D., Bowtell, D., et al. (2009). Evidence that inositol polyphosphate 4-phosphatase type II is a tumor suppressor that inhibits PI3K signaling. Cancer Cell 16, 115-125.

Geyer, F.C., Lacroix-Triki, M., Savage, K., Arnedos, M., Lambros, M.B., MacKay, A., et al. (2011). $\beta$-Catenin pathway activation in breast cancer is associated with triple-negative phenotype but not with CTNNB1 mutation. Mod. Pathol. 24, 209-231.

Gilmore, H., Varadan, V., Williams, N., Thompson, C.L., Kim, S., Hsu, P., et al. (2015). Abstract P3-04-07: Androgen receptor expression in triple negative breast cancer. Cancer Res. 75, P3-P04 - 07-P3 - 04-07.

Goel, H.L., and Mercurio, A.M. (2013). VEGF targets the tumour cell. Nat. Rev. Cancer 13, 871-882.

Gökmen-Polar, Y., Liu, Y., Toroni, R.A., Sanders, K.L., Mehta, R., Badve, S., et al. (2012). Investigational drug MLN0128, a novel TORC1/2 inhibitor, demonstrates potent oral antitumor activity in human breast cancer xenograft models. Breast Cancer Res. Treat. 136, 673-682.

Goldenberg, D.M., Cardillo, T.M., Govindan, S. V, Rossi, E.A., and Sharkey, R.M. (2015). Trop-2 is a novel target for solid cancer therapy with sacituzumab govitecan (IMMU-132), an antibody-drug conjugate (ADC). Oncotarget.

Gonzalez, G., Crombet, T., Torres, F., Catala, M., Alfonso, L., Osorio, M., et al. (2003). Epidermal growth factor-based cancer vaccine for non-small-cell lung cancer therapy. Ann. Oncol. 14, 461-466.

Gonzalez, L.O., Corte, M.D., Vazquez, J., Junquera, S., Sanchez, R., Alvarez, A.C., et al. (2008). Androgen receptor expresion in breast cancer: relationship with clinicopathological characteristics of the tumors, prognosis, and expression of metalloproteases and their inhibitors. BMC Cancer 8, 149. 
Gonzalez-Angulo, A.M., Morales-Vasquez, F., and Hortobagyi, G.N. (2007). Overview of resistance to systemic therapy in patients with breast cancer. Adv. Exp. Med. Biol. 608, 1-22.

Gonzalez-Angulo, A.M., Krop, I., Akcakanat, A., Chen, H., Liu, S., Li, Y., et al. (2015). SU2C phase Ib study of paclitaxel and MK-2206 in advanced solid tumors and metastatic breast cancer. J. Natl. Cancer Inst. 107.

Grosso, J.F., and Jure-Kunkel, M.N. (2013). CTLA-4 blockade in tumor models: an overview of preclinical and translational research. Cancer Immun. 13, 5.

Gschwind, A., Fischer, O.M., and Ullrich, A. (2004). The discovery of receptor tyrosine kinases: targets for cancer therapy. Nat. Rev. Cancer 4, 361-370.

Gucalp, A., Tolaney, S., Isakoff, S.J., Ingle, J.N., Liu, M.C., Carey, L.A., et al. (2013). Phase II trial of bicalutamide in patients with androgen receptor-positive, estrogen receptor-negative metastatic Breast Cancer. Clin. Cancer Res. 19, 5505-5512.

Guo, S., Colbert, L.S., Fuller, M., Zhang, Y., and Gonzalez-Perez, R.R. (2010). Vascular endothelial growth factor receptor-2 in breast cancer. Biochim. Biophys. Acta - Rev. Cancer 1806, 108-121.

Gupta, N., Solis, W.A., Fuji, R.N., Oldendorp, A., Pacheco, G., Luis, E., et al. (2014). Abstract 4502:

Nonclinical characterization and tolerability of a surrogate anti-mesothelin-MMAE antibody-drug conjugate. Cancer Res. 74, 4502-4502.

Gupta, S., Argiles, G., Munster, P.N., Hollebecque, A., Dajani, O., Cheng, J., et al. (2015). A Phase I Trial of Combined Ridaforolimus and MK-2206 in Patients With Advanced Malignancies. Clin. Cancer Res. 10780432.CCR - 15-0180 - .

Hanahan, D., and Coussens, L.M. (2012). Accessories to the crime: functions of cells recruited to the tumor microenvironment. Cancer Cell 21, 309-322.

Hao, N.-B., Lü, M.-H., Fan, Y.-H., Cao, Y.-L., Zhang, Z.-R., and Yang, S.-M. (2012). Macrophages in Tumor Microenvironments and the Progression of Tumors. Clin. Dev. Immunol. 2012, 1-11.

Harding, T.C., Long, L., Palencia, S., Zhang, H., Sadra, A., Hestir, K., et al. (2013). Blockade of nonhormonal fibroblast growth factors by FP-1039 inhibits growth of multiple types of cancer. Sci. Transl. Med. 5, 178ra39.

Heldin, C.-H. (2013). Targeting the PDGF signaling pathway in tumor treatment. Cell Commun. Signal. 11, 97.

Heroult, M., Ellinghaus, P., Sieg, C., Brohm, D., Gruenewald, S., Collin, M.-P., et al. (2014). Abstract 1739: Preclinical profile of BAY 1163877 - a selective pan-FGFR inhibitor in phase 1 clinical trial. Cancer Res. 74, 1739-1739. 
Hidalgo, M., Cooray, P., Jameson, M.B., Carrato, A., Parnis, F., Jeffery, M., et al. (2015). A phase Ib study of the anti-cancer stem cell agent demcizumab (DEM) \& gemcitabine (GEM) +/- paclitaxel protein bound particles (nab-paclitaxel) in pts with pancreatic cancer. J Clin Oncol 33, suppl; abstr 4118.

Holohan, C., Van Schaeybroeck, S., Longley, D.B., and Johnston, P.G. (2013). Cancer drug resistance: an evolving paradigm. Nat. Rev. Cancer 13, 714-726.

Hopkins, T.A., Shi, Y., Rodriguez, L.E., Solomon, L.R., Donawho, C.K., Digiammarino, E.L., et al. (2015). Mechanistic Dissection of PARP1 Trapping and the Impact on in vivo Tolerability and Efficacy of PARP Inhibitors. Mol. Cancer Res.

Howe, L.R., and Brown, A.M.C. (2004). Wnt signaling and breast cancer. Cancer Biol. Ther. 3, 36-41.

Ho-Yen, C.M., Jones, J.L., and Kermorgant, S. (2015). The clinical and functional significance of c-Met in breast cancer: a review. Breast Cancer Res. 17, 52.

Hu, R., Dawood, S., Holmes, M.D., Collins, L.C., Schnitt, S.J., Cole, K., et al. (2011). Androgen receptor expression and breast cancer survival in postmenopausal women. Clin. Cancer Res. 17, 1867-1874.

Hudis, C., Swanton, C., Janjigian, Y.Y., Lee, R., Sutherland, S., Lehman, R., et al. (2013). A phase 1 study evaluating the combination of an allosteric AKT inhibitor (MK-2206) and trastuzumab in patients with HER2positive solid tumors. Breast Cancer Res. 15, R110.

Huebschman, M.L., Lane, N.L., Liu, H., Sarode, V.R., Devlin, J.L., and Frenkel, E.P. (2015). Molecular heterogeneity in adjacent cells in triple-negative breast cancer. Breast Cancer (Dove Med. Press. 7, 231-237.

Hynes, N.E. (2000). Tyrosine kinase signalling in breast cancer. Breast Cancer Res. 2, 154-157.

Ibrahim, S.A., Hassan, H., Vilardo, L., Kumar, S.K., Kumar, A.V., Kelsch, R., et al. (2013). Syndecan-1 (CD138) modulates triple-negative breast cancer stem cell properties via regulation of LRP-6 and IL-6mediated STAT3 signaling. PLoS One 8, e85737.

Iguchi, H., Nogami, N., Kozuki, T, Matsumoto, T., Tamura, K., Yamamoto, N., et al; (2015). Phase I study to evaluate the safety and tolerability of MEDI4736, an anti-programmed cell death ligand-1 (PD-L1) antibody, in Japanese patients with advanced solid tumors. J Clin Oncol 33, suppl; abstr 3039.

Imbimbo, B.P. (2008). Therapeutic potential of gamma-secretase inhibitors and modulators. Curr. Top. Med. Chem. 8, 54-61.

Isakoff, S.J., Bendell, J.C., Cervantes, A., Soria, J.-C., Molife, L.R., Sanabria-Bohorquez, S.M., et al. (2015). Abstract P6-12-02: Phase Ib dose-escalation study of an Akt inhibitor ipatasertib (Ipat) in combination with docetaxel (Doc) or paclitaxel (Pac) in patients (pts) with metastatic breast cancer (MBC). Cancer Res. 75, P6P12 - 02-P6 - 12-02. 
Isakoff, S.J., Overmoyer, B., Tung, N.M., Gelman, R.S., Giranda, V.L., Bernhard, K.M., et al. (2010). A phase II trial of the PARP inhibitor veliparib (ABT888) and temozolomide for metastatic breast cancer. $J$ Clin Oncol 28:15s, suppl; abstr 1019.

Iversen, T.Z., Andersen, M.H., and Svane, I.M. (2015). The targeting of indoleamine 2,3 dioxygenase -mediated immune escape in cancer. Basic Clin. Pharmacol. Toxicol. 116, 19-24.

Jaakkola, S., Salmikangas, P., Nylund, S., Partanen, J., Armstrong, E., Pyrhönen, S., et al. (1993). Amplification of fgfr4 gene in human breast and gynecological cancers. Int. J. Cancer 54, 378-382.

Jechlinger, M., Sommer, A., Moriggl, R., Seither, P., Kraut, N., Capodiecci, P., et al. (2006). Autocrine PDGFR signaling promotes mammary cancer metastasis. J. Clin. Invest. 116, 1561-1570.

Jin, H., Tu, D., Zhao, N., Shepherd, L.E., and Goss, P.E. (2012). Longer-term outcomes of letrozole versus placebo after 5 years of tamoxifen in the NCIC CTG MA.17 trial: analyses adjusting for treatment crossover. J. Clin. Oncol. 30, 718-721.

Jin, Y., Chauhan, S.K., El Annan, J., Annan, J.E.I., Sage, P.T., Sharpe, A.H., et al. (2011). A novel function for programmed death ligand-1 regulation of angiogenesis. Am. J. Pathol. 178, 1922-1929.

Junttila, M.R., and de Sauvage, F.J. (2013). Influence of tumour micro-environment heterogeneity on therapeutic response. Nature 501, 346-354.

Juric, D., Saura, C., Cervantes, A., Kurkjian, C., Patel, M., Sachdev, J., et al. (2014). Abstract PD1-3: Ph1b study of the PI3K inhibitor GDC-0032 in combination with fulvestrant in patients with hormone receptorpositive advanced breast cancer. Cancer Res. 73, PD1-PD3 - PD1-PD3.

Juric, D., De Bono, J.S., LoRusso, P., Nemunaitis, J.J., Heath, E.I., Kwak, E.L., et al. (2015). First-in-human, phase I, dose-escalation study of selective PI3K $\alpha$ isoform inhibitor MLN1117 in patients (pts) with advanced solid malignancies. J Clin Oncol 33, suppl; abstr 2501.

Karnezis, T., Shayan, R., Caesar, C., Roufail, S., Harris, N.C., Ardipradja, K., et al. (2012). VEGF-D promotes tumor metastasis by regulating prostaglandins produced by the collecting lymphatic endothelium. Cancer Cell 21, 181-195.

Karnoub, A.E., Dash, A.B., Vo, A.P., Sullivan, A., Brooks, M.W., Bell, G.W., et al. (2007). Mesenchymal stem cells within tumour stroma promote breast cancer metastasis. Nature 449, 557-563.

Kashiwagi, S., Yashiro, M., Takashima, T., Aomatsu, N., Kawajiri, H., Ogawa, Y., et al. (2013). c-Kit expression as a prognostic molecular marker in patients with basal-like breast cancer. Br. J. Surg. 100, 490496.

Katz, J.B., Muller, A.J., and Prendergast, G.C. (2008). Indoleamine 2,3-dioxygenase in T-cell tolerance and tumoral immune escape. Immunol. Rev. 222, 206-221. 
Kaufman, B., Shapira-Frommer, R., Schmutzler, R.K., Audeh, M.W., Friedlander, M., Balmana, J., et al. (2014). Olaparib Monotherapy in Patients With Advanced Cancer and a Germline BRCA1/2 Mutation. J. Clin. Oncol. 33, 244-250.

Kelly, K., Patel, M.R., Infante, J.R., Iannotti, N., Nikolinakos, P., Leach, P., et al. (2015). Avelumab (MSB0010718C), an anti-PD-L1 antibody, in patients with metastatic or locally advanced solid tumors: assessment of safety and tolerability in a phase I, open-label expansion study. J Clin Oncol 33, suppl; abstr 3044.

Van Keymeulen, A., Lee, M.Y., Ousset, M., Brohée, S., Rorive, S., Giraddi, R.R., et al. (2015). Reactivation of multipotency by oncogenic PIK3CA induces breast tumour heterogeneity. Nature 525, 119-123.

Kim, N., and Cho, S.-G. (2013). Clinical applications of mesenchymal stem cells. Korean J. Intern. Med. 28, 387-402.

Kim, D., Dan, H.C., Park, S., Yang, L., Liu, Q., Kaneko, S., et al. (2005). AKT/PKB signaling mechanisms in cancer and chemoresistance. Front. Biosci. 10, 975-987.

Kitamura, T., Qian, B.-Z., and Pollard, J.W. (2015). Immune cell promotion of metastasis. Nat. Rev. Immunol. 15, 73-86.

Kohrt, H.E., Houot, R., Weiskopf, K., Goldstein, M.J., Scheeren, F., Czerwinski, D., et al. (2012). Stimulation of natural killer cells with a CD137-specific antibody enhances trastuzumab efficacy in xenotransplant models of breast cancer. J. Clin. Invest. 122, 1066-1075.

Kolasa, I.K., Rembiszewska, A., Felisiak, A., Ziolkowska-Seta, I., Murawska, M., Moes, J., et al. (2009). PIK3CA amplification associates with resistance to chemotherapy in ovarian cancer patients. Cancer Biol. Ther. 8, 21-26.

Kono, S.A., Marshall, M.E., Ware, K.E., and Heasley, L.E. (2009). The fibroblast growth factor receptor signaling pathway as a mediator of intrinsic resistance to EGFR-specific tyrosine kinase inhibitors in nonsmall cell lung cancer. Drug Resist. Updat. 12, 95-102.

Koren, S., Reavie, L., do Couto, J.P., De Silva, D., Stadler, M.B., Roloff, T., et al. (2015). PIK3CAH1047R induces multipotency and multi-lineage mammary tumours. Nature advance on.

Korkaya, H., Liu, S., and Wicha, M.S. (2011). Breast cancer stem cells, cytokine networks, and the tumor microenvironment. J. Clin. Invest. 121, 3804-3809.

Kreike, B., van Kouwenhove, M., Horlings, H., Weigelt, B., Peterse, H., Bartelink, H., et al. (2007). Gene expression profiling and histopathological characterization of triple-negative/basal-like breast carcinomas . Breast Cancer Res. 9, R65. 
Krop, I., Demuth, T., Guthrie, T., Wen, P.Y., Mason, W.P., Chinnaiyan, P., et al. (2012). Phase I pharmacologic and pharmacodynamic study of the gamma secretase (Notch) inhibitor MK-0752 in adult patients with advanced solid tumors. J. Clin. Oncol. 30, 2307-2313.

Krop, I., Johnston, S., Mayer, I.A., Dickler, M., Ganju, V., Forero-Torres, A., et al. (2015). Abstract S2-02: The FERGI phase II study of the PI3K inhibitor pictilisib (GDC-0941) plus fulvestrant vs fulvestrant plus placebo in patients with ER+, aromatase inhibitor (AI)-resistant advanced or metastatic breast cancer - Part I results. Cancer Res. 75, S2-02 - S2-02.

Kummar, S., Chen, A., Parchment, R.E., Kinders, R.J., Ji, J., Tomaszewski, J.E., et al. (2012). Advances in using PARP inhibitors to treat cancer. BMC Med. 10, 25.

Lamberts, L.E., de Groot, D.J.A., Bense, R.D., de Vries, E.G.E., and Fehrmann, R.S.N. (2015). Functional genomic mRNA Profiling of a large cancer data base demonstrates mesothelin overexpression in a broad range of tumor types. Oncotarget.

Landskron, G., De la Fuente, M., Thuwajit, P., Thuwajit, C., and Hermoso, M.A. (2014). Chronic inflammation and cytokines in the tumor microenvironment. J. Immunol. Res. 2014, 149185.

Langley, R.R., and Fidler, I.J. (2011). The seed and soil hypothesis revisited--the role of tumor-stroma interactions in metastasis to different organs. Int. J. Cancer 128, 2527-2535.

Lee, C.P., Taylor, N.J., Attard, G., Pacey, S., Nathan, P.D., de Bono, J.S., et al. (2015). Phase I study of nintedanib incorporating dynamic contrast-enhanced magnetic resonance imaging in patients with advanced solid tumors. Oncologist 20, 368-369.

Lee, J.-M., Hays, J.L., Annunziata, C.M., Noonan, A.M., Minasian, L., Zujewski, J.A., et al. (2014). Phase I/Ib study of olaparib and carboplatin in BRCA1 or BRCA2 mutation-associated breast or ovarian cancer with biomarker analyses. J. Natl. Cancer Inst. 106, dju089.

Van der Lee, M.M.C., Groothuis, P.G., Ubink, R., van der Vleuten, M.A.J., van Achterberg, T.A., Loosveld, E.M., et al. (2015). The Preclinical Profile of the Duocarmycin-Based HER2-Targeting ADC SYD985 Predicts for Clinical Benefit in Low HER2-Expressing Breast Cancers. Mol. Cancer Ther. 14, 692-703.

Lee-Hoeflich, S.T., Crocker, L., Yao, E., Pham, T., Munroe, X., Hoeflich, K.P., et al. (2008). A central role for HER3 in HER2-amplified breast cancer: implications for targeted therapy. Cancer Res. 68, 5878-5887.

Lehmann, B.D., Bauer, J.A., Chen, X., Sanders, M.E., Chakravarthy, A.B., Shyr, Y., et al. (2011). Identification of human triple-negative breast cancer subtypes and preclinical models for selection of targeted therapies. J. Clin. Invest. 121, 2750-2767.

Lehmann, B.D., Bauer, J.A., Schafer, J.M., Pendleton, C.S., Tang, L., Johnson, K.C., et al. (2014). PIK3CA mutations in androgen receptor-positive triple negative breast cancer confer sensitivity to the combination of PI3K and androgen receptor inhibitors. Breast Cancer Res. 16, 406. 
Leong, S.R., Liang, W.-C., Wu, Y., Crocker, L., Cheng, E., Sampath, D., et al. (2015). An anti-B7-H4 antibody-drug conjugate for the treatment of breast cancer. Mol. Pharm. 12, 1717-1729.

Lieu, C., Heymach, J., Overman, M., Tran, H., and Kopetz, S. (2011). Beyond VEGF: inhibition of the fibroblast growth factor pathway and antiangiogenesis. Clin. Cancer Res. 17, 6130-6139.

Lin, S.Y., Xia, W., Wang, J.C., Kwong, K.Y., Spohn, B., Wen, Y., et al. (2000). Beta-catenin, a novel prognostic marker for breast cancer: its roles in cyclin D1 expression and cancer progression. Proc. Natl. Acad. Sci. U. S. A. 97, 4262-4266.

Lipton, A., Fizazi, K., Stopeck, A.T., Henry, D.H., Brown, J.E., Yardley, D.A., et al. (2012). Superiority of denosumab to zoledronic acid for prevention of skeletal-related events: a combined analysis of 3 pivotal, randomised, phase 3 trials. Eur. J. Cancer 48, 3082-3092.

Liu, P., Cheng, H., Roberts, T.M., and Zhao, J.J. (2009). Targeting the phosphoinositide 3-kinase pathway in cancer. Nat. Rev. Drug Discov. 8, 627-644.

Liu, S., Ginestier, C., Ou, S.J., Clouthier, S.G., Patel, S.H., Monville, F., et al. (2011). Breast cancer stem cells are regulated by mesenchymal stem cells through cytokine networks. Cancer Res. 71, 614-624.

Liyanage, U.K., Moore, T.T., Joo, H.-G., Tanaka, Y., Herrmann, V., Doherty, G., et al. (2002). Prevalence of Regulatory T Cells Is Increased in Peripheral Blood and Tumor Microenvironment of Patients with Pancreas or Breast Adenocarcinoma. J. Immunol. 169, 2756-2761.

Loibl, S., Müller, B.M., von Minckwitz, G., Schwabe, M., Roller, M., Darb-Esfahani, S., et al. (2011). Androgen receptor expression in primary breast cancer and its predictive and prognostic value in patients treated with neoadjuvant chemotherapy. Breast Cancer Res. Treat. 130, 477-487.

López-Knowles, E., O’Toole, S.A., McNeil, C.M., Millar, E.K.A., Qiu, M.R., Crea, P., et al. (2010). PI3K pathway activation in breast cancer is associated with the basal-like phenotype and cancer-specific mortality. Int. J. Cancer 126, 1121-1131.

LoRusso, P., Krop, I., Miller, K., Ma, C., Siegel, B.A., Shields, A.F., et al. (2015a). Abstract CT234: A phase I study of MM-302, a HER2-targeted PEGylated liposomal doxorubicin, in patients with HER2+ metastatic breast cancer. Cancer Res. 75, СT234-CT234.

LoRusso, P.M., Tolaney, S.M., Wong, S., Parchment, R.E., Kinders, R.J., Wang, L., et al. (2015b). Abstract CT325: Combination of the PARP inhibitor veliparib (ABT888) with irinotecan in patients with triple negative breast cancer: Preliminary activity and signature of response. Cancer Res. 75, CT325-CT325.

Lu, P., Weaver, V.M., and Werb, Z. (2012). The extracellular matrix: a dynamic niche in cancer progression. $J$. Cell Biol. 196, 395-406.

Luo, X., Shi, Y.-X., Li, Z.-M., and Jiang, W.-Q. (2010). Expression and clinical significance of androgen receptor in triple negative breast cancer. Chin. J. Cancer 29, 585-590. 
Luo, Y., Zhou, H., Krueger, J., Kaplan, C., Lee, S.-H., Dolman, C., et al. (2006). Targeting tumor-associated macrophages as a novel strategy against breast cancer. J. Clin. Invest. 116, 2132-2141.

Lutzky, J., Antonia, S.J., Blake-Haskins, A., Li, X., Robbins, P.B., Shalabi, A.M., et al. (2014). A phase 1 study of MEDI4736, an anti-PD-L1 antibody, in patients with advanced solid tumors. J Clin Oncol 32:5s, suppl; abstr 3001.

Madar, S., Goldstein, I., and Rotter, V. (2013). “Cancer associated fibroblasts”--more than meets the eye. Trends Mol. Med. 19, 447-453.

Mahmoud, S.M.A., Paish, E.C., Powe, D.G., Macmillan, R.D., Grainge, M.J., Lee, A.H.S., et al. (2011). Tumor-Infiltrating CD8+ Lymphocytes Predict Clinical Outcome in Breast Cancer. J. Clin. Oncol. 29, 19491955.

Malanchi, I., Santamaria-Martínez, A., Susanto, E., Peng, H., Lehr, H.-A., Delaloye, J.-F., et al. (2012). Interactions between cancer stem cells and their niche govern metastatic colonization. Nature 481, 85-89.

Malgieri, A., Kantzari, E., Patrizi, M.P., and Gambardella, S. (2010). Bone marrow and umbilical cord blood human mesenchymal stem cells: state of the art. Int. J. Clin. Exp. Med. 3, 248-269.

Malhotra, B., and Schuetze, S.M. (2012). Dermatofibrosarcoma protruberans treatment with platelet-derived growth factor receptor inhibitor: a review of clinical trial results. Curr. Opin. Oncol. 24, 419-424.

Mao, Y., Keller, E.T., Garfield, D.H., Shen, K., and Wang, J. (2013). Stromal cells in tumor microenvironment and breast cancer. Cancer Metastasis Rev. 32, 303-315.

Martin, M., Bell, R., Bourgeois, H., Brufsky, A., Diel, I., Eniu, A., et al. (2012). Bone-related complications and quality of life in advanced breast cancer: results from a randomized phase III trial of denosumab versus zoledronic acid. Clin. Cancer Res. 18, 4841-4849.

Martini, M., De Santis, M.C., Braccini, L., Gulluni, F., and Hirsch, E. (2014). PI3K/AKT signaling pathway and cancer: an updated review. Ann. Med. 46, 372-383.

Masuda, H., Zhang, D., Bartholomeusz, C., Doihara, H., Hortobagyi, G.N., and Ueno, N.T. (2012). Role of epidermal growth factor receptor in breast cancer. Breast Cancer Res. Treat. 136, 331-345.

Matulonis, U.A., Wulf, G., Barry, W., Birrer, M., Westin, S., Spagnoletti, T., et al. (2015). Abstract CT324: Phase I of oral BKM120 or BYL719 and olaparib for high-grade serous ovarian cancer or triple-negative breast cancer: Final results of the BKM120 plus olaparib cohort. Cancer Res. 75, CT324-CT324.

Mayer, I.A., Abramson, V.G., Isakoff, S.J., Forero, A., Balko, J.M., Kuba, M.G., et al. (2014). Stand up to cancer phase Ib study of pan-phosphoinositide-3-kinase inhibitor buparlisib with letrozole in estrogen receptor-positive/human epidermal growth factor receptor 2-negative metastatic breast cancer. J. Clin. Oncol. 32, 1202-1209. 
McGhan, L.J., McCullough, A.E., Protheroe, C.A., Dueck, A.C., Lee, J.J., Nunez-Nateras, R., et al. (2014). Androgen receptor-positive triple negative breast cancer: a unique breast cancer subtype. Ann. Surg. Oncol. 21, 361-367.

McGray, A.J.R., Hallett, R., Bernard, D., Swift, S.L., Zhu, Z., Teoderascu, F., et al. (2014). Immunotherapyinduced CD8+ T cells instigate immune suppression in the tumor. Mol. Ther. 22, 206-218.

McKeage, M.J., Kotasek, D., Markman, B., Hidalgo, M., Millward, M., Jameson. M.B., et al. (2014). A phase $1 \mathrm{~b}$ study of the anti-cancer stem cell agent demcizumab (DEM), pemetrexed (PEM) \& carboplatin (CARBO) in pts with 1st line non-squamous NSCLC. | 2015 ASCO Annual Meeting | Abstracts | Meeting Library. J Clin Oncol 32:5s, suppl; abstr 2544.

Meadows, K.L., and Hurwitz, H.I. (2012). Anti-VEGF therapies in the clinic. Cold Spring Harb. Perspect. Med. 2, a006577.

Melero, I., Gaudernack, G., Gerritsen, W., Huber, C., Parmiani, G., Scholl, S., et al. (2014). Therapeutic vaccines for cancer: an overview of clinical trials. Nat. Rev. Clin. Oncol. 11, 509-524.

Mendoza, M.C., Er, E.E., and Blenis, J. (2011). The Ras-ERK and PI3K-mTOR pathways: cross-talk and compensation. Trends Biochem. Sci. 36, 320-328.

Messersmith, W.A., LoRusso, P.M., Cleary, J.M., Dasari, A., Huang, B., Shaik, N.M., et al. (2012). 588 A First-in-patient Phase I Study of the Novel Gamma Secretase Inhibitor PF-03084014 in Patients with Advanced Solid Tumor Malignancies. Eur. J. Cancer 48, 180.

Messersmith, W.A., Shapiro, G.I., Cleary, J.M., Jimeno, A., Dasari, A., Huang, B., et al. (2015). A Phase I, dose-finding study in patients with advanced solid malignancies of the oral $\gamma$-secretase inhibitor PF-03084014. Clin. Cancer Res. 21, 60-67.

Metzger-Filho, O., Tutt, A., de Azambuja, E., Saini, K.S., Viale, G., Loi, S., et al. (2012). Dissecting the heterogeneity of triple-negative breast cancer. J. Clin. Oncol. 30, 1879-1887.

Mi, Z., Bhattacharya, S.D., Kim, V.M., Guo, H., Talbot, L.J., and Kuo, P.C. (2011). Osteopontin promotes CCL5-mesenchymal stromal cell-mediated breast cancer metastasis. Carcinogenesis 32, 477-487.

Miller, T.W., Pérez-Torres, M., Narasanna, A., Guix, M., Stål, O., Pérez-Tenorio, G., et al. (2009). Loss of Phosphatase and Tensin homologue deleted on chromosome 10 engages ErbB3 and insulin-like growth factorI receptor signaling to promote antiestrogen resistance in breast cancer. Cancer Res. 69, 4192-4201.

Millward, M., Underhill, C., Lobb, S., McBurnie, J., Meech, S.J., Gomez-Navarro, J., et al. (2013). Phase I study of tremelimumab (CP-675 206) plus PF-3512676 (CPG 7909) in patients with melanoma or advanced solid tumours. Br. J. Cancer 108, 1998-2004. 
Molife, L.R., Yan, L., Vitfell-Rasmussen, J., Zernhelt, A.M., Sullivan, D.M., Cassier, P.A., et al. (2014). Phase 1 trial of the oral AKT inhibitor MK-2206 plus carboplatin/paclitaxel, docetaxel, or erlotinib in patients with advanced solid tumors. J. Hematol. Oncol. 7, 1.

Montagna, E., Maisonneuve, P., Rotmensz, N., Cancello, G., Iorfida, M., Balduzzi, A., et al. (2013). Heterogeneity of triple-negative breast cancer: histologic subtyping to inform the outcome. Clin. Breast Cancer 13, 31-39.

Morales, J.K., Kmieciak, M., Knutson, K.L., Bear, H.D., and Manjili, M.H. (2010). GM-CSF is one of the main breast tumor-derived soluble factors involved in the differentiation of CD11b-Gr1- bone marrow progenitor cells into myeloid-derived suppressor cells. Breast Cancer Res. Treat. 123, 39-49.

Mougiakakos, D., Choudhury, A., Lladser, A., Kiessling, R., and Johansson, C.C. (2010). Regulatory T cells in cancer. Adv. Cancer Res. 107, 57-117.

Murai, J., Huang, S.N., Das, B.B., Renaud, A., Zhang, Y., Doroshow, J.H., et al. (2012). Trapping of PARP1 and PARP2 by Clinical PARP Inhibitors. Cancer Res. 72, 5588-5599.

Murphy, C.G., and Morris, P.G. (2012). Recent advances in novel targeted therapies for HER2-positive breast cancer. Anticancer. Drugs 23, 765-776.

Nagata, Y., Lan, K.-H., Zhou, X., Tan, M., Esteva, F.J., Sahin, A.A., et al. (2004). PTEN activation contributes to tumor inhibition by trastuzumab, and loss of PTEN predicts trastuzumab resistance in patients. Cancer Cell $6,117-127$.

Nahta, R., Yu, D., Hung, M.-C., Hortobagyi, G.N., and Esteva, F.J. (2006). Mechanisms of disease: understanding resistance to HER2-targeted therapy in human breast cancer. Nat. Clin. Pract. Oncol. 3, 269280.

Nanda, R., Chow, L.Q., Dees, E.C., Berger, R., Gupta, S., Geva, R., et al. (2015). Abstract S1-09: A phase Ib study of pembrolizumab (MK-3475) in patients with advanced triple-negative breast cancer. Cancer Res. 75, S1-S09 - S1-S09.

Narazaki, H., Zhu, Y., Luo, L., Zhu, G., and Chen, L. (2010). CD137 agonist antibody prevents cancer recurrence: contribution of CD137 on both hematopoietic and nonhematopoietic cells. Blood 115, 1941-1948.

Nemunaitis, J.J., Adams, N., Bedell, C., Klucher, K., Taylor, J., Whiting, S.H., et al. (2014). Tolerability, humoral immune response, and disease control in phase 1 patients receiving ONT-10, a MUC1 liposomal vaccine. J Clin Oncol 32:5s, suppl; abstr 3091.

Ngiow, S.F., von Scheidt, B., Akiba, H., Yagita, H., Teng, M.W.L., and Smyth, M.J. (2011). Anti-TIM3 antibody promotes $\mathrm{T}$ cell IFN- $\gamma$-mediated antitumor immunity and suppresses established tumors. Cancer Res. 71, 3540-3551. 
Nguyen, L.T., and Ohashi, P.S. (2014). Clinical blockade of PD1 and LAG3 — potential mechanisms of action. Nat. Rev. Immunol. 15, 45-56.

Nguyen, M., Miyakawa, S., Kato, J., Mori, T., Arai, T., Armanini, M., et al. (2015). Preclinical Efficacy and Safety Assessment of an Antibody Drug Conjugate Targeting the c-RET Proto-oncogene for Breast Carcinoma. Clin. Cancer Res.

Nielsen, D.L., Andersson, M., and Kamby, C. (2009). HER2-targeted therapy in breast cancer. Monoclonal antibodies and tyrosine kinase inhibitors. Cancer Treat. Rev. 35, 121-136.

Niemeier, L.A., Dabbs, D.J., Beriwal, S., Striebel, J.M., and Bhargava, R. (2010). Androgen receptor in breast cancer: expression in estrogen receptor-positive tumors and in estrogen receptor-negative tumors with apocrine differentiation. Mod. Pathol. 23, 205-212.

Van der Noll, R., Marchetti, S., Steeghs, N., Beijnen, J.H., Mergui-Roelvink, M.W.J., Harms, E., et al. (2015). Long-term safety and anti-tumour activity of olaparib monotherapy after combination with carboplatin and paclitaxel in patients with advanced breast, ovarian or fallopian tube cancer. Br. J. Cancer 113, 396-402.

Nombela-Arrieta, C., Ritz, J., and Silberstein, L.E. (2011). The elusive nature and function of mesenchymal stem cells. Nat. Rev. Mol. Cell Biol. 12, 126-131.

Nowsheen, S., Cooper, T., Stanley, J.A., and Yang, E.S. (2012). Synthetic lethal interactions between EGFR and PARP inhibition in human triple negative breast cancer cells. PLoS One 7, e46614.

Noy, R., and Pollard, J.W. (2014). Tumor-Associated Macrophages: From Mechanisms to Therapy. Immunity 41, 49-61.

O’Shaughnessy, J., Campone, M., Brain, E., Neven, P., Hayes, D.F., Bondarenko, I., et al. (2014). Randomized phase 2 study of abiraterone acetate (AA) with or without exemestane (E) in postmenopausal patients (pts) with estrogen receptor-positive (ER+) metastatic breast cancer (MBC). J Clin Oncol 32:5s, suppl; abstr 519.

Oh, K., Lee, O.-Y., Shon, S.Y., Nam, O., Ryu, P.M., Seo, M.W., et al. (2013). A mutual activation loop between breast cancer cells and myeloid-derived suppressor cells facilitates spontaneous metastasis through IL-6 trans-signaling in a murine model. Breast Cancer Res. 15, R79.

Ohshio, Y., Teramoto, K., Hanaoka, J., Tezuka, N., Itoh, Y., Asai, T., et al. (2015). Cancer-associated fibroblast-targeted strategy enhances antitumor immune responses in dendritic cell-based vaccine. Cancer Sci. 106, 134-142.

Olsauskas-Kuprys, R., Zlobin, A., and Osipo, C. (2013). Gamma secretase inhibitors of Notch signaling. Onco. Targets. Ther. 6, 943-955.

Onitilo, A.A., Engel, J.M., Greenlee, R.T., and Mukesh, B.N. (2009). Breast cancer subtypes based on ER/PR and Her2 expression: comparison of clinicopathologic features and survival. Clin. Med. Res. 7, 4-13. 
Ono, M., Kosaka, N., Tominaga, N., Yoshioka, Y., Takeshita, F., Takahashi, R., et al. (2014). Exosomes from bone marrow mesenchymal stem cells contain a microRNA that promotes dormancy in metastatic breast cancer cells. Sci. Signal. 7, ra63.

Overmoyer, B., Sanz-Altimira, P., Partridge, A.H., Extermann, M., Liu, J., Winer, E., et al. (2015). Abstract P1-13-04: Enobosarm for the treatment of metastatic, estrogen and androgen receptor positive, breast cancer. Final results of the primary endpoint and current progression free survival. Cancer Res. 75, P1-P13 - 04-P1 $13-04$.

Page, D.B., Naidoo, J., and McArthur, H.L. (2014). Emerging immunotherapy strategies in breast cancer. Immunotherapy 6, 195-209.

Pahuja, S., Beumer, J.H., Appleman, L.J., Tawbi, H.A., Stoller, R.G., Lee, J.J., et al. (2015). A phase I study of veliparib (ABT-888) in combination with weekly carboplatin and paclitaxel in advanced solid malignancies and enriched for triple-negative breast cancer (TNBC). J Clin Oncol 33, suppl; abstr 1015.

Palazón, A., Teijeira, A., Martínez-Forero, I., Hervás-Stubbs, S., Roncal, C., Peñuelas, I., et al. (2011). Agonist anti-CD137 mAb act on tumor endothelial cells to enhance recruitment of activated T lymphocytes. Cancer Res. 71, 801-811.

Papadopoulos, K.P., Tabernero, J., Markman, B., Patnaik, A., Tolcher, A.W., Baselga, J., et al. (2014). Phase I safety, pharmacokinetic, and pharmacodynamic study of SAR245409 (XL765), a novel, orally administered PI3K/mTOR inhibitor in patients with advanced solid tumors. Clin. Cancer Res. 20, 2445-2456.

Pardoll, D.M. (2012). The blockade of immune checkpoints in cancer immunotherapy. Nat. Rev. Cancer 12, 252-264.

Park, S., Koo, J.S., Kim, M.S., Park, H.S., Lee, J.S., Kim, S.I., et al. (2011). Androgen receptor expression is significantly associated with better outcomes in estrogen receptor-positive breast cancers. Ann. Oncol. 22, 1755-1762.

Parry, R. V, Chemnitz, J.M., Frauwirth, K.A., Lanfranco, A.R., Braunstein, I., Kobayashi, S. V, et al. (2005). CTLA-4 and PD-1 receptors inhibit T-cell activation by distinct mechanisms. Mol. Cell. Biol. 25, 9543-9553.

Patel, S.A., Meyer, J.R., Greco, S.J., Corcoran, K.E., Bryan, M., and Rameshwar, P. (2010). Mesenchymal stem cells protect breast cancer cells through regulatory T cells: role of mesenchymal stem cell-derived TGFbeta. J. Immunol. 184, 5885-5894.

Paulsson, J., Sjöblom, T., Micke, P., Pontén, F., Landberg, G., Heldin, C.-H., et al. (2009). Prognostic significance of stromal platelet-derived growth factor beta-receptor expression in human breast cancer. Am. $J$. Pathol. 175, 334-341.

Pece, S., Serresi, M., Santolini, E., Capra, M., Hulleman, E., Galimberti, V., et al. (2004). Loss of negative regulation by Numb over Notch is relevant to human breast carcinogenesis. J. Cell Biol. 167, 215-221. 
Penault-Llorca, F., Bertucci, F., Adélaïde, J., Parc, P., Coulier, F., Jacquemier, J., et al. (1995). Expression of FGF and FGF receptor genes in human breast cancer. Int. J. Cancer 61, 170-176.

Pestano, L.A., Christian, B., Koppenol, S., Millard, J., Christianson, G., Klucher, K., et al. (2014). Abstract 762: ONT-10, a liposomal vaccine targeting hypoglycosylated MUC1, induces a potent cellular and humoral response and suppresses the growth of MUC1 expressing tumors. Cancer Res. 71, 762-762.

Pietras, K., and Ostman, A. (2010). Hallmarks of cancer: interactions with the tumor stroma. Exp. Cell Res. 316, 1324-1331.

Pignatelli, J., Goswami, S., Jones, J.G., Rohan, T.E., Pieri, E., Chen, X., et al. (2014). Invasive breast carcinoma cells from patients exhibit MenaINV- and macrophage-dependent transendothelial migration. Sci. Signal. 7, ra112.

Place, A.E., Jin Huh, S., and Polyak, K. (2011). The microenvironment in breast cancer progression: biology and implications for treatment. Breast Cancer Res. 13, 227.

Pollak, M. (2008). Insulin and insulin-like growth factor signalling in neoplasia. Nat. Rev. Cancer 8, 915-928.

Postow, M.A., Callahan, M.K., and Wolchok, J.D. (2015). Immune Checkpoint Blockade in Cancer Therapy. J. Clin. Oncol. JCO.2014.59.4358 - .

Pothuri, B. (2013). BRCA1- and BRCA2-related mutations: therapeutic implications in ovarian cancer. Ann. Oncol. 24 Suppl 8, viii22-viii27.

Prendergast, G.C. (2008). Immune escape as a fundamental trait of cancer: focus on IDO. Oncogene 27, 3889-3900.

Prendergast, G.C., Smith, C., Thomas, S., Mandik-Nayak, L., Laury-Kleintop, L., Metz, R., et al. (2014). Indoleamine 2,3-dioxygenase pathways of pathogenic inflammation and immune escape in cancer. Cancer Immunol. Immunother. 63, 721-735.

Puhalla, S., Han, H.S., Dieras, V., Friedlander, M., Somlo, G., Arun, B., et al. (2015). Phase 3 randomized, placebo-controlled trial of carboplatin (C) and paclitaxel (P) with/without veliparib (ABT-888) in HER2BRCA-associated locally advanced or metastatic breast cancer (BC). ASCO Meet. Abstr. 33, TPS1102.

Puhalla, S., Beumer, J.H., Pahuja, S., Appleman, L.J., Tawbi, H.A., Stoller, R.G., et al. (2014). Final results of a phase 1 study of single-agent veliparib (V) in patients (pts) with either BRCA1/2-mutated cancer (BRCA+), platinum-refractory ovarian, or basal-like breast cancer (BRCA-wt). J Clin Oncol 32:5s, suppl; abstr 2570.

Qian, B.-Z., and Pollard, J.W. (2010). Macrophage diversity enhances tumor progression and metastasis. Cell $141,39-51$. 
Quintela-Fandino, M., Urruticoechea, A., Guerra, J., Gil, M., Gonzalez-Martin, A., Marquez, R., et al. (2014). Phase I clinical trial of nintedanib plus paclitaxel in early HER-2-negative breast cancer (CNIO-BR-012010/GEICAM-2010-10 study). Br. J. Cancer 111, 1060-1064.

Raghav, K.P., Wang, W., Liu, S., Chavez-MacGregor, M., Meng, X., Hortobagyi, G.N., et al. (2012). cMET and phospho-cMET protein levels in breast cancers and survival outcomes. Clin. Cancer Res. 18, 2269-2277.

Rakha, E.A., El-Sayed, M.E., Green, A.R., Lee, A.H.S., Robertson, J.F., and Ellis, I.O. (2007). Prognostic markers in triple-negative breast cancer. Cancer 109, 25-32.

Rampurwala, M.M., Burkard, M.E., Wisinski, K.B., Chimeh, S.E., Zeal, J., Koehn, T., et al. (2014). Phase 1b study of orteronel in postmenopausal women with hormone-receptor positive $(\mathrm{HR}+)$ metastatic breast cancer. J Clin Oncol 32:5s, suppl; abstr 538.

Rapraeger, A.C. (2013). Synstatin: a selective inhibitor of the syndecan-1-coupled IGF1R- $\alpha v \beta 3$ integrin complex in tumorigenesis and angiogenesis. FEBS J. 280, 2207-2215.

Redmond, W.L., Linch, S.N., and Kasiewicz, M.J. (2014). Combined targeting of costimulatory (OX40) and coinhibitory (CTLA-4) pathways elicits potent effector T cells capable of driving robust antitumor immunity. Cancer Immunol. Res. 2, 142-153.

Regan, J.L., Kendrick, H., Magnay, F.-A., Vafaizadeh, V., Groner, B., and Smalley, M.J. (2012). c-Kit is required for growth and survival of the cells of origin of Brca1-mutation-associated breast cancer. Oncogene 31, 869-883.

Ren, G., Esposito, M., and Kang, Y. (2015). Bone metastasis and the metastatic niche. J. Mol. Med. (Berl).

Ries, C.H., Cannarile, M.A., Hoves, S., Benz, J., Wartha, K., Runza, V., et al. (2014). Targeting tumorassociated macrophages with anti-CSF-1R antibody reveals a strategy for cancer therapy. Cancer Cell 25, 846-859.

Robinson, B.D., Sica, G.L., Liu, Y.-F., Rohan, T.E., Gertler, F.B., Condeelis, J.S., et al. (2009). Tumor Microenvironment of Metastasis in Human Breast Carcinoma: A Potential Prognostic Marker Linked to Hematogenous Dissemination. Clin. Cancer Res. 15, 2433-2441.

Robinson, D.R., Kalyana-Sundaram, S., Wu, Y.-M., Shankar, S., Cao, X., Ateeq, B., et al. (2011). Functionally recurrent rearrangements of the MAST kinase and Notch gene families in breast cancer. Nat. Med. 17, 16461651.

Robinson, D.R., Wu, Y.-M., Vats, P., Su, F., Lonigro, R.J., Cao, X., et al. (2013). Activating ESR1 mutations in hormone-resistant metastatic breast cancer. Nat. Genet. 45, 1446-1451.

Rohan, T.E., Xue, X., Lin, H.-M., D’Alfonso, T.M., Ginter, P.S., Oktay, M.H., et al. (2014). Tumor microenvironment of metastasis and risk of distant metastasis of breast cancer. J. Natl. Cancer Inst. 106. 
Rouleau, M., Patel, A., Hendzel, M.J., Kaufmann, S.H., and Poirier, G.G. (2010). PARP inhibition: PARP1 and beyond. Nat. Rev. Cancer 10, 293-301.

Roussos, E.T., Balsamo, M., Alford, S.K., Wyckoff, J.B., Gligorijevic, B., Wang, Y., et al. (2011). Mena invasive (MenaINV) promotes multicellular streaming motility and transendothelial migration in a mouse model of breast cancer. J. Cell Sci. 124, 2120-2131.

Roy, A.K., Lavrovsky, Y., Song, C.S., Chen, S., Jung, M.H., Velu, N.K., et al. (1998). Regulation of Androgen Action. Vitam. Horm. 55, 309-352.

Ruffell, B., Chang-Strachan, D., Chan, V., Rosenbusch, A., Ho, C.M.T., Pryer, N., et al. (2014). Macrophage IL-10 Blocks CD8+ T Cell-Dependent Responses to Chemotherapy by Suppressing IL-12 Expression in Intratumoral Dendritic Cells. Cancer Cell 26, 623-637.

Rugo, H.S., Tredan, O., Ro, J., Morales, S., Musolino, A., Afonso, N., et al. (2015). Abstract PD5-1: Results from the phase 2 trial of ridaforolimus, dalotuzumab, and exemestane compared to ridaforolimus and exemestane in advanced breast cancer. Cancer Res. 75, PD5-1 - PD5-1.

Sahebjam, S., Bedard, P.L., Castonguay, V., Chen, Z., Reedijk, M., Liu, G., et al. (2013). A phase I study of the combination of ro4929097 and cediranib in patients with advanced solid tumours (PJC-004/NCI 8503). Br. J. Cancer 109, 943-949.

Sakuishi, K., Apetoh, L., Sullivan, J.M., Blazar, B.R., Kuchroo, V.K., and Anderson, A.C. (2010). Targeting Tim-3 and PD-1 pathways to reverse T cell exhaustion and restore anti-tumor immunity. J. Exp. Med. 207, 2187-2194.

Salgado, R., Denkert, C., Demaria, S., Sirtaine, N., Klauschen, F., Pruneri, G., et al. (2015). The evaluation of tumor-infiltrating lymphocytes (TILs) in breast cancer: recommendations by an International TILs Working Group 2014. Ann. Oncol. 26, 259-271.

Sandhu, S.K., Schelman, W.R., Wilding, G., Moreno, V., Baird, R.D., Miranda, S., et al. (2013). The poly(ADP-ribose) polymerase inhibitor niraparib (MK4827) in BRCA mutation carriers and patients with sporadic cancer: a phase 1 dose-escalation trial. Lancet. Oncol. 14, 882-892.

Sandhu, S.K., Wenham, R.M., Wilding, G., McFadden, M., Sun, L., Toniatti, C., et al. (2010). First-in-human trial of a poly(ADP-ribose) polymerase (PARP) inhibitor MK-4827 in advanced cancer patients (pts) with antitumor activity in BRCA-deficient and sporadic ovarian cancers. J Clin Oncol 28:15s, suppl; abstr 3001.

Sarker, D., Ang, J.E., Baird, R., Kristeleit, R., Shah, K., Moreno, V., et al. (2015). First-in-human phase I study of pictilisib (GDC-0941), a potent pan-class I phosphatidylinositol-3-kinase (PI3K) inhibitor, in patients with advanced solid tumors. Clin. Cancer Res. 21, 77-86.

Sassoon, I., and Blanc, V. (2013). Antibody-drug conjugate (ADC) clinical pipeline: a review. Methods Mol. Biol. 1045, 1-27. 
Saura, C., Sachdev, J., Patel, M.R., Cervantes, A., Juric, D., Infante, J.R., et al. (2015). Abstract PD5-2: Ph1b study of the PI3K inhibitor taselisib (GDC-0032) in combination with letrozole in patients with hormone receptor-positive advanced breast cancer. Cancer Res. 75, PD5-2 - PD5-2.

Scales, S.J., Gupta, N., Pacheco, G., Firestein, R., French, D.M., Chuh, J., et al. (2014). Abstract 4494: A clinical candidate anti-mesothelin-MMAE antibody-drug conjugate (ADC) for therapy of mesothelinexpressing cancers. Cancer Res. 74, 4494-4494.

Schott, A.F., Landis, M.D., Dontu, G., Griffith, K.A., Layman, R.M., Krop, I., et al. (2013). Preclinical and clinical studies of gamma secretase inhibitors with docetaxel on human breast tumors. Clin. Cancer Res. 19, 1512-1524.

Segal, N.H., Antonia, S.J., Brahmer, J.R., Maio, M., Blake-Haskins, A., Li, X., et al. (2014). Preliminary data from a multi-arm expansion study of MEDI4736, an anti-PD-L1 antibody. J Clin Oncol 32:5s, suppl; abstr 3002.

Seiler, M., Ray-Coquard, I., Melichar, B., Yardley, D.A., Wang, R.X., Dodion, P.F., et al. (2015). Oral ridaforolimus plus trastuzumab for patients with HER2+ trastuzumab-refractory metastatic breast cancer. Clin. Breast Cancer 15, 60-65.

Sequist, L. V., Cassier, P., Varga, A., Tabernero, J., Schellens, J.H., Delord, J.-P., et al. (2014). Abstract CT326: Phase I study of BGJ398, a selective pan-FGFR inhibitor in genetically preselected advanced solid tumors. Cancer Res. 74, CT326-CT326.

Sethi, N., Dai, X., Winter, C.G., and Kang, Y. (2011). Tumor-derived JAGGED1 promotes osteolytic bone metastasis of breast cancer by engaging notch signaling in bone cells. Cancer Cell 19, 192-205.

Shah, P.D., Moynahan, M.E., Modi, S., Hamilton, N., Caravella, B.A., Zamora, S., et al. (2015). Abstract CT330: Phase I study of PI3Ka inhibitor BYL719 + aromatase inhibitor (AI) in patients (pts) with hormone receptor-positive (HR+) metastatic breast cancer (MBC). Cancer Res. 75, CT330-CT330.

Shah, P.D., Chandarlapaty, S., Dickler, M.N., Ulaner, G., Zamora, S.J., Sterlin, V., et al. (2015). Phase I study of LJM716, BYL719, and trastuzumab in patients (pts) with HER2-amplified (HER2+) metastatic breast cancer (MBC). J Clin Oncol 33, suppl; abstr 590.

Shah, P.D., Modi, S., Datko, F.M., Moynahan, M.E., Zamora, S., D’Andrea, G., et al. (2014). Phase I trial of daily PI3Ka inhibitor BYL719 plus letrozole (L) or exemestane (E) for patients (pts) with hormone receptorpositive (HR+) metastatic breast cancer (MBC). J Clin Oncol 32:5s, suppl; abstr 2605.

Shapiro, G., Kristeleit, R., Middleton, M., Burris, H., Molife, L.R., Evans, J., et al. (2014). Abstract A218: Pharmacokinetics of orally administered rucaparib in patients with advanced solid tumors. Mol. Cancer Ther. 12, A218-A218. 
Sharkey, R.M., McBride, W.J., Cardillo, T.M., Govindan, S. V, Wang, Y., Rossi, E.A., et al. (2015). Enhanced Delivery of SN-38 to Human Tumor Xenografts with an Anti-Trop-2-SN-38 Antibody Conjugate (Sacituzumab Govitecan). Clin. Cancer Res.

Sharma, P., and Allison, J.P. (2015). The future of immune checkpoint therapy. Science (80-. ). 348, 56-61.

Shen, Y., Rehman, F.L., Feng, Y., Boshuizen, J., Bajrami, I., Elliott, R., et al. (2013). BMN 673, a novel and highly potent PARP1/2 inhibitor for the treatment of human cancers with DNA repair deficiency. Clin. Cancer Res. 19, 5003-5015.

Shih, I.-M., and Wang, T.-L. (2007). Notch signaling, gamma-secretase inhibitors, and cancer therapy. Cancer Res. 67, 1879-1882.

Sierra, J.R., and Tsao, M.-S. (2011). c-MET as a potential therapeutic target and biomarker in cancer. Ther. Adv. Med. Oncol. 3, S21-S35.

Sievers, E.L., and Senter, P.D. (2013). Antibody-drug conjugates in cancer therapy. Annu. Rev. Med. 64, 1529.

Singh, J.C., Jhaveri, K., and Esteva, F.J. (2014). HER2-positive advanced breast cancer: optimizing patient outcomes and opportunities for drug development. Br. J. Cancer 111, 1888-1898.

Sirohi, B., Rastogi, S., and Dawood, S. (2015). Buparlisib in breast cancer. Future Oncol. 11, 1463-1470.

Skobe, M., Hawighorst, T., Jackson, D.G., Prevo, R., Janes, L., Velasco, P., et al. (2001). Induction of tumor lymphangiogenesis by VEGF-C promotes breast cancer metastasis. Nat. Med. 7, 192-198.

Sledge, G.W. (2015). Anti-vascular endothelial growth factor therapy in breast cancer: game over? J. Clin. Oncol. 33, 133-135.

Smyth, E.C., Turner, N.C., Peckitt, C., Pearson, A., Brown, G., Chua, S., et al. (2015). Phase II multicenter proof of concept study of AZD4547 in FGFR amplified tumours. J Clin Oncol 33, suppl; abstr 2508.

Soliman, H.H., Jackson, E., Neuger, T., Dees, C.E., Harvey, D.R., Han, H., et al. (2014). A first in man phase I trial of the oral immunomodulator, indoximod, combined with docetaxel in patients with metastatic solid tumors. Oncotarget 5, 8136-8146.

Soliman, H.H., Minton, S.E., Ismail-Khan, R., Han, H.S., Vahanian, N.N., Link, C.J., et al. (2015). Abstract P2-15-04: A phase 1/2 study of Ad.p53 DC vaccine with indoximod immunotherapy in metastatic breast cancer. Cancer Res. 75, P2-P15 - 04-P2 - 15-04.

Somlo, G., Frankel, P.H., Luu, T.H., Ma, C., Arun, B., Garcia, A., et al. (2014). Phase II trial of single agent PARP inhibitor ABT-888 (veliparib [vel]) followed by postprogression therapy of vel with carboplatin (carb) in patients (pts) with stage BRCA-associated metastatic breast cancer (MBC): California Cancer Consortium trial PHII. J Clin Oncol 32:5s, suppl; abstr 1021. 
Sonnenblick, A., de Azambuja, E., Azim, H.A., and Piccart, M. (2014). An update on PARP inhibitors-moving to the adjuvant setting. Nat. Rev. Clin. Oncol. 12, 27-41.

Soria, J.-C., DeBraud, F., Bahleda, R., Adamo, B., Andre, F., Dienstmann, R., et al. (2014). Phase I/IIa study evaluating the safety, efficacy, pharmacokinetics, and pharmacodynamics of lucitanib in advanced solid tumors. Ann. Oncol. 25, 2244-2251.

Soria, J.-C., LoRusso, P., Bahleda, R., Lager, J., Liu, L., Jiang, J., et al. (2015). Phase I dose-escalation study of pilaralisib (SAR245408, XL147), a pan-class I PI3K inhibitor, in combination with erlotinib in patients with solid tumors. Oncologist 20, 245-246.

Sounni, N.E., Cimino, J., Blacher, S., Primac, I., Truong, A., Mazzucchelli, G., et al. (2014). Blocking lipid synthesis overcomes tumor regrowth and metastasis after antiangiogenic therapy withdrawal. Cell Metab. 20, 280-294.

Srabovic, N., Mujagic, Z., Mujanovic-Mustedanagic, J., Softic, A., Muminovic, Z., Rifatbegovic, A., et al. (2013). Vascular endothelial growth factor receptor-1 expression in breast cancer and its correlation to vascular endothelial growth factor a. Int. J. Breast Cancer 2013, 746749.

Stacchiotti, S., Longhi, A., Ferraresi, V., Grignani, G., Comandone, A., Stupp, R., et al. (2012). Phase II study of imatinib in advanced chordoma. J. Clin. Oncol. 30, 914-920.

Stagg, J., and Allard, B. (2013). Immunotherapeutic approaches in triple-negative breast cancer: latest research and clinical prospects. Ther. Adv. Med. Oncol. 5, 169-181.

Stanley, E.R., and Chitu, V. (2014). CSF-1 receptor signaling in myeloid cells. Cold Spring Harb. Perspect. Biol. 6, a021857 - .

Starodub, A.N., Ocean, A., Shah, M.A., Guarino, M.J., Picozzi, V.J., Vahdat, L.T., et al. (2015). First-inHuman Trial of a Novel Anti-Trop-2 Antibody-SN-38 conjugate, Sacituzumab Govitecan, for the Treatment of Diverse Metastatic Solid Tumors. Clin. Cancer Res.

Stoeck, A., Lejnine, S., Truong, A., Pan, L., Wang, H., Zang, C., et al. (2014). Discovery of biomarkers predictive of GSI response in triple-negative breast cancer and adenoid cystic carcinoma. Cancer Discov. 4, 1154-1167.

Stopeck, A.T., Lipton, A., Body, J.-J., Steger, G.G., Tonkin, K., de Boer, R.H., et al. (2010). Denosumab compared with zoledronic acid for the treatment of bone metastases in patients with advanced breast cancer: a randomized, double-blind study. J. Clin. Oncol. 28, 5132-5139.

Stylianou, S., Clarke, R.B., and Brennan, K. (2006). Aberrant activation of notch signaling in human breast cancer. Cancer Res. 66, 1517-1525. 
Sun, Y., De, P., Carlson, J.H., Friedman, L., Dey, N., and Leyland-Jones, B. (2015). Abstract 4717: In vitro potency of dual PI3K/mTORC1/C2 inhibitor, GDC-0980 in ER+ and HER2 overexpressing breast cancer cells. Cancer Res. 75, 4717-4717.

Sussman, D., Smith, L.M., Anderson, M.E., Duniho, S., Hunter, J.H., Kostner, H., et al. (2014). SGN-LIV1A: a novel antibody-drug conjugate targeting LIV-1 for the treatment of metastatic breast cancer. Mol. Cancer Ther. 13, 2991-3000.

Sutton, L.M., Cao, D., Sarode, V., Molberg, K.H., Torgbe, K., Haley, B., et al. (2012). Decreased androgen receptor expression is associated with distant metastases in patients with androgen receptor-expressing triplenegative breast carcinoma. Am. J. Clin. Pathol. 138, 511-516.

Tabernero, J., Bahleda, R., Dienstmann, R., Infante, J.R., Mita, A., Italiano, A., et al. (2015). Phase I DoseEscalation Study of JNJ-42756493, an Oral Pan-Fibroblast Growth Factor Receptor Inhibitor, in Patients With Advanced Solid Tumors. J. Clin. Oncol.

Talmadge, J.E., and Gabrilovich, D.I. (2013). History of myeloid-derived suppressor cells. Nat. Rev. Cancer 13, 739-752.

Tan, W., Zhang, W., Strasner, A., Grivennikov, S., Cheng, J.Q., Hoffman, R.M., et al. (2011). Tumourinfiltrating regulatory $\mathrm{T}$ cells stimulate mammary cancer metastasis through RANKL-RANK signalling. Nature 470, 548-553.

Templeton, A.J., Diez-Gonzalez, L., Ace, O., Vera-Badillo, F., Seruga, B., Jordán, J., et al. (2014). Prognostic relevance of receptor tyrosine kinase expression in breast cancer: a meta-analysis. Cancer Treat. Rev. 40, 1048-1055.

Tenhagen, M., van Diest, P.J., Ivanova, I.A., van der Wall, E., and van der Groep, P. (2012). Fibroblast growth factor receptors in breast cancer: expression, downstream effects, and possible drug targets. Endocr. Relat. Cancer 19, R115-R129.

The Cancer Genome Atlas Network (2012). Comprehensive molecular portraits of human breast tumours. Nature 490, 61-70.

Thomas, L.J., He, L.-Z., Wasiuk, A., Gergel, L.E., Boyer, J.M., Round, S.M., et al. (2015). Abstract 253: Synergistic antitumor activity of PD-1 signaling blockade and CD27 costimulation correlates with enhanced ratio of effector to regulatory T cells at the tumor site. Cancer Res. 75, 253-253.

Tokunaga, E., Kimura, Y., Mashino, K., Oki, E., Kataoka, A., Ohno, S., et al. (2006). Activation of PI3K/Akt signaling and hormone resistance in breast cancer. Breast Cancer 13, 137-144.

Tolaney, S., Burris, H., Gartner, E., Mayer, I.A., Saura, C., Maurer, M., et al. (2015). Phase I/II study of pilaralisib (SAR245408) in combination with trastuzumab or trastuzumab plus paclitaxel in trastuzumabrefractory HER2-positive metastatic breast cancer. Breast Cancer Res. Treat. 149, 151-161. 
Tolcher, A.W., Messersmith, W.A., Mikulski, S.M., Papadopoulos, K.P., Kwak, E.L., Gibbon, D.G., et al. (2012). Phase I study of RO4929097, a gamma secretase inhibitor of Notch signaling, in patients with refractory metastatic or locally advanced solid tumors. J. Clin. Oncol. 30, 2348-2353.

Tolcher, A.W., Chugh, R., Chambers, G., Thorpe, V., Dupont, J., Hill, D., et al. (2012). A first-in-human phase I study to evaluate the fully human monoclonal antibody OMP-59R5 (anti-Notch2/3) administered intravenously to patients with advanced solid tumors. J Clin Oncol 30, suppl; abstr 3025.

Topalian, S.L., Drake, C.G., and Pardoll, D.M. (2015). Immune Checkpoint Blockade: A Common Denominator Approach to Cancer Therapy. Cancer Cell 27, 450-461.

Toy, W., Shen, Y., Won, H., Green, B., Sakr, R.A., Will, M., et al. (2013). ESR1 ligand-binding domain mutations in hormone-resistant breast cancer. Nat. Genet. 45, 1439-1445.

Traina, T.A., Miller, K., Yardley, D.A., O’Shaughnessy, J., Cortes, J., Awada, A., et al. (2015). Results from a phase 2 study of enzalutamide (ENZA), an androgen receptor (AR) inhibitor, in advanced AR+ triple-negative breast cancer (TNBC). J Clin Oncol 33, suppl; abstr 1003.

Turner, N., and Grose, R. (2010). Fibroblast growth factor signalling: from development to cancer. Nat. Rev. Cancer 10, 116-129.

Turner, N., Lambros, M.B., Horlings, H.M., Pearson, A., Sharpe, R., Natrajan, R., et al. (2010). Integrative molecular profiling of triple negative breast cancers identifies amplicon drivers and potential therapeutic targets. Oncogene 29, 2013-2023.

Tutt, A., Robson, M., Garber, J.E., Domchek, S.M., Audeh, M.W., Weitzel, J.N., et al. (2010). Oral poly(ADPribose) polymerase inhibitor olaparib in patients with BRCA1 or BRCA2 mutations and advanced breast cancer: a proof-of-concept trial. Lancet (London, England) 376, 235-244.

Vaklavas, C., and Forero, A. (2014). Management of metastatic breast cancer with second-generation antibody-drug conjugates: focus on glembatumumab vedotin (CDX-011, CR011-vcMMAE). BioDrugs 28, 253-263.

Velasco-Velázquez, M.A., Homsi, N., De La Fuente, M., and Pestell, R.G. (2012). Breast cancer stem cells. Int. J. Biochem. Cell Biol. 44, 573-577.

Vera-Badillo, F.E., Templeton, A.J., de Gouveia, P., Diaz-Padilla, I., Bedard, P.L., Al-Mubarak, M., et al. (2014). Androgen receptor expression and outcomes in early breast cancer: a systematic review and metaanalysis. J. Natl. Cancer Inst. 106, djt319.

Voduc, K.D., Cheang, M.C.U., Tyldesley, S., Gelmon, K., Nielsen, T.O., and Kennecke, H. (2010). Breast cancer subtypes and the risk of local and regional relapse. J. Clin. Oncol. 28, 1684-1691.

Voron, T., Marcheteau, E., Pernot, S., Colussi, O., Tartour, E., Taieb, J., et al. (2014). Control of the immune response by pro-angiogenic factors. Front. Oncol. 4, 70. 
Wagner, A.J., Bendell, J.C., Dolly, S., Morgan, J.A., Ware, J.A., Fredrickson, J., et al. (2011). A first-in-human phase I study to evaluate GDC-0980, an oral PI3K/mTOR inhibitor, administered QD in patients with advanced solid tumors. ASCO Meet. Abstr. 29, 3020.

Wainberg, Z.A., de Bono, J.S., Mina, L., Sachdev, J., Byers, L.A., Chugh, R., et al. (2014). Abstract C295: Update on first-in-man trial of novel oral PARP inhibitor BMN 673 in patients with solid tumors. Mol. Cancer Ther. 12, C295-C295.

Wang, Y., Cairo, S., Deas, O., Hartman, A.-R., Jones, J., Gutin, A., et al. (2015). Abstract P5-06-04: The PARP inhibitor niraparib demonstrated activity in patient-derived triple-negative breast cancer xenograft models with high homologous recombination deficiency (HRD) score. Cancer Res. 75, P5-P06 - 04-P5 - 06-04.

Weil, M.K., and Chen, A.P. (2011). PARP Inhibitor Treatment in Ovarian and Breast Cancer. Curr. Probl. Cancer 35, 7-50.

Wesche, J., Haglund, K., and Haugsten, E.M. (2011). Fibroblast growth factors and their receptors in cancer. Biochem. J. 437, 199-213.

Whiteside, T.L. (2008). The tumor microenvironment and its role in promoting tumor growth. Oncogene 27, 5904-5912.

Wimberly, H., Brown, J.R., Schalper, K., Haack, H., Silver, M.R., Nixon, C., et al. (2015). PD-L1 Expression Correlates with Tumor-Infiltrating Lymphocytes and Response to Neoadjuvant Chemotherapy in Breast Cancer. Cancer Immunol. Res. 3, 326-332.

Wise-Draper, T., Moorthy, G., Salkeni, M., Thomas, H., Mercer, C., Kozma, S., et al. (2015). P1.14 * A Dose Escalation Single Arm Phase Ib Combination Study of BEZ235 with Everolimus in Patients with Advanced Solid Malignancies. Ann. Oncol. 26, ii19-ii19.

Wolff, A.C., Lazar, A.A., Bondarenko, I., Garin, A.M., Brincat, S., Chow, L., et al. (2013). Randomized phase III placebo-controlled trial of letrozole plus oral temsirolimus as first-line endocrine therapy in postmenopausal women with locally advanced or metastatic breast cancer. J. Clin. Oncol. 31, 195-202.

Wong, S.C.C., Lo, S.F.E., Lee, K.C., Yam, J.W.P., Chan, J.K.C., and Wendy Hsiao, W.L. (2002). Expression of frizzled-related protein and Wnt-signalling molecules in invasive human breast tumours. J. Pathol. 196, 145153.

Woo, S.-R., Turnis, M.E., Goldberg, M. V, Bankoti, J., Selby, M., Nirschl, C.J., et al. (2012). Immune inhibitory molecules LAG-3 and PD-1 synergistically regulate T-cell function to promote tumoral immune escape. Cancer Res. 72, 917-927.

Yakes, F.M., Chinratanalab, W., Ritter, C.A., King, W., Seelig, S., and Arteaga, C.L. (2002). Herceptininduced inhibition of phosphatidylinositol-3 kinase and Akt Is required for antibody-mediated effects on p27, cyclin D1, and antitumor action. Cancer Res. 62, 4132-4141. 
Yang, Y., and Yee, D. (2012). Targeting insulin and insulin-like growth factor signaling in breast cancer. $J$. Mammary Gland Biol. Neoplasia 17, 251-261.

Yardley, D.A., Weaver, R., Melisko, M.E., Saleh, M.N., Arena, F.P., Forero, A., et al. (2015). EMERGE: A Randomized Phase II Study of the Antibody-Drug Conjugate Glembatumumab Vedotin in Advanced Glycoprotein NMB-Expressing Breast Cancer. J. Clin. Oncol. 33, 1609-1619.

Yen, W.-C., Fischer, M.M., Axelrod, F., Bond, C., Cain, J., Cancilla, B., et al. (2015). Targeting Notch signaling with a Notch2/Notch3 antagonist (tarextumab) inhibits tumor growth and decreases tumor-initiating cell frequency. Clin. Cancer Res. 21, 2084-2095.

Yu, Y., Xiao, C.-H., Tan, L.-D., Wang, Q.-S., Li, X.-Q., and Feng, Y.-M. (2014). Cancer-associated fibroblasts induce epithelial-mesenchymal transition of breast cancer cells through paracrine TGF- $\beta$ signalling. $B r . J$. Cancer 110, 724-732.

Zhang, S., Chen, L., Cui, B., Chuang, H.-Y., Yu, J., Wang-Rodriguez, J., et al. (2012). ROR1 is expressed in human breast cancer and associated with enhanced tumor-cell growth. PLoS One 7, e31127.

Zhang, X.H.-F., Jin, X., Malladi, S., Zou, Y., Wen, Y.H., Brogi, E., et al. (2013). Selection of bone metastasis seeds by mesenchymal signals in the primary tumor stroma. Cell 154, 1060-1073. 


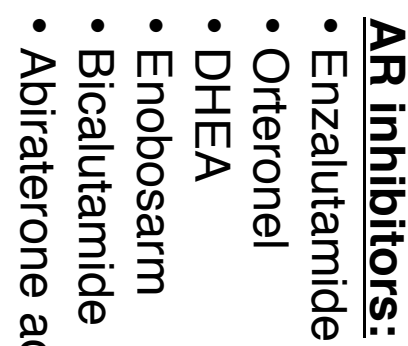

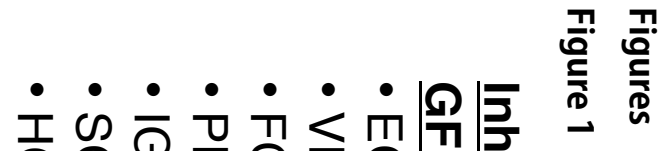

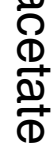
กฺ

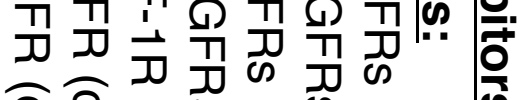
ลิ?

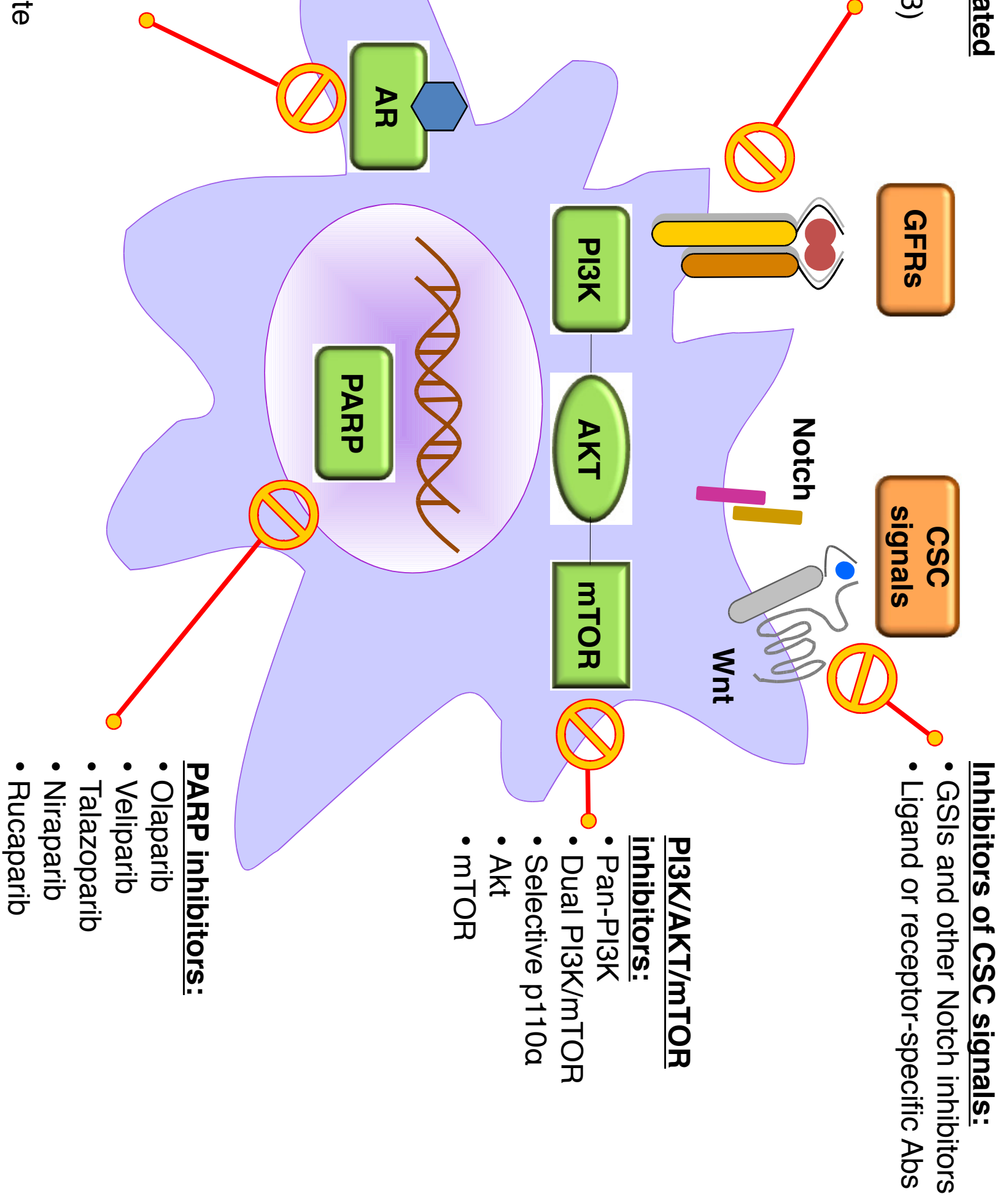




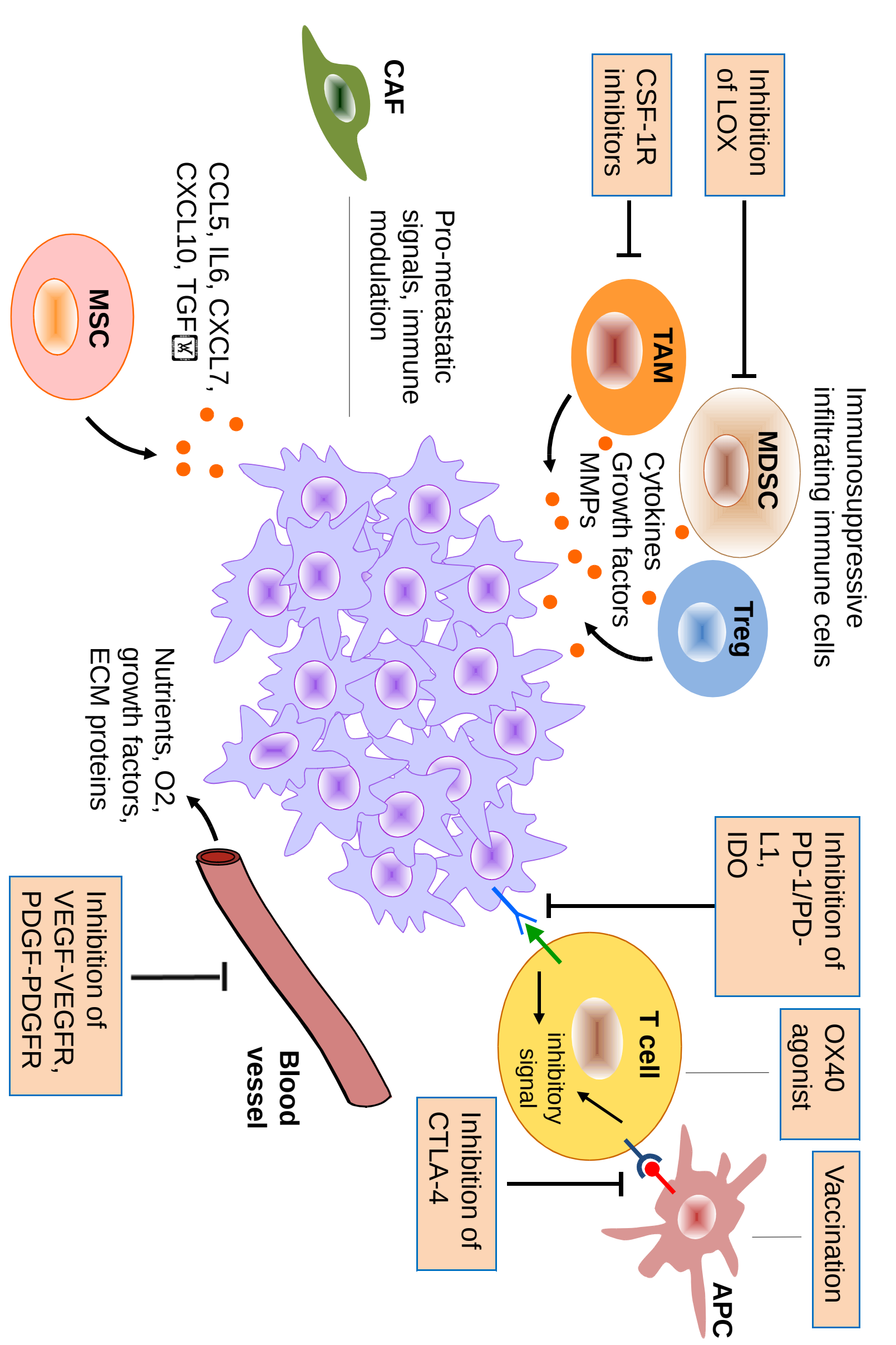

